\title{
CRÍTICO, COMISARIO Y CINEASTA EXPERIMENTAL: NÉSTOR ALMENDROS EN NUEVA YORK, 1957-19591
}

Film Critic, Curator, and Experimental Filmmaker: Néstor Almendros in New York, 1957-1959

BREIXO VIEJO ${ }^{a}$

Barnard College, Columbia University DOI: $10.15366 /$ secuencias2021.53.001

\begin{abstract}
RESUMEN
El reconocimiento internacional de Néstor Almendros (1930-1992) como director de fotografía ha eclipsado, dentro de la historia convencional del cine, otras dos facetas fundamentales de su trayectoria: la de crítico cinematográfico y la de director de cine experimental y documental. Este artículo analiza las actividades profesionales de Almendros durante el comienzo de su carrera en Nueva York, entre 1957 y 1959, y estudia con detenimiento su producción como comisario (para el cineclub de Vassar College), como crítico (para Film Culture) y como director de cine experimental (con los cortometrajes de vanguardia, El monte de la luna y 58-59). A su vez, y a través de un estudio crítico de materiales de archivo inéditos, propone una nueva lectura de la obra de Almendros que tiene en cuenta su carácter multidisciplinar y resitúa al cineasta como una de las figuras principales del cine español en el exilio.
\end{abstract}

Palabras claves: Néstor Almendros, cine español en el exilio, cine experimental, El monte de la luna (1958), 58-59 (1959), Film Group de Vassar College, Film Culture.

[1] Mi agradecimiento por su inestimable ayuda a Jesús Gómez y Belén Piqueras, Almansa; Lluís Cerarols, Calders; Teresa López, Laureano Bonet y Daniel Jiménez Schlegl, Barcelona; Esteve Riambau, Filmoteca de Catalunya, Barcelona; Antonio Gosálvez, Instituto Néstor Almendros, Sevilla; Nicolas Dulac, Cinémathèque Québécoise, y David Lavoie, Mels Studios, Montreal; Dean Rogers, Vassar College, Poughkeepsie; Danielle Rougeau, Middlebury College, Middlebury; Sydney van Nort, City College, Nueva York; y al personal de Butler Library y New York Public Library for the Performing Arts, Nueva York. Gracias también a Aurora Albertos, John y Robert Benton, Isabel Custodio, Alvin Friedman-Kien, Pere Gimferrer, Miriam Gómez, Juan Goytisolo, Román Gubern, Jaume Perecaula, Chema Prado, Germán Puig, Teresa Picañol, Joan Serra, Faustino Tamarit, José Tamarit Póveda y Jorge Ulla, por compartir conmigo sus recuerdos de Almendros.

\begin{abstract}
The international recognition of Néstor Almendros (1930-1992) as a cinematographer has overshadowed -within conventional film studies- two other fundamental aspects of his career: his work in film criticism and in experimental and documentary film making. This essay analizes Almendros' activities during the early years of his professional life in New York, from 1957 to 1959 , by studying in detail his outcome as a film curator (for Vassar College's Film Group), as a film critic (for Film Culture) and as an experimental film maker (with two avant-garde shorts, The Mount of Luna and 58-59). Through a critical study of previously unpublished archival materials, this paper presents a new interpretation of Almendros' multidisciplinary career and reconsiders him as one of the major figures of Spanish cinema in exile.
\end{abstract}

Keywords: Néstor Almendros, Spanish cinema in exile, experimental film, The Mount of Luna (1958), 58-59 (1959), Vassar College Film Group, Film Culture.

[a] Breixo Viejo es profesor de cine en Barnard College, Columbia University, Nueva York. Entre sus publicaciones recientes destacan el libro Film Books: A Visual History (Oak Knoll Press, 2016) y la edición, junto a Jo Evans, de Luis Buñuel: A Life in Letters (Bloomsbury, 2019). Doctor en Historia del Cine por la Universidad Autónoma de Madrid, obtuvo su maestría en Media Studies en la New School for Social Research de Nueva York. Ha publicado numerosos textos sobre historia y estética de cine para revistas como Archivos de la Filmoteca, Bulletin of Spanish Studies y Secuencias. E-mail: bv2147@columbia.edu 


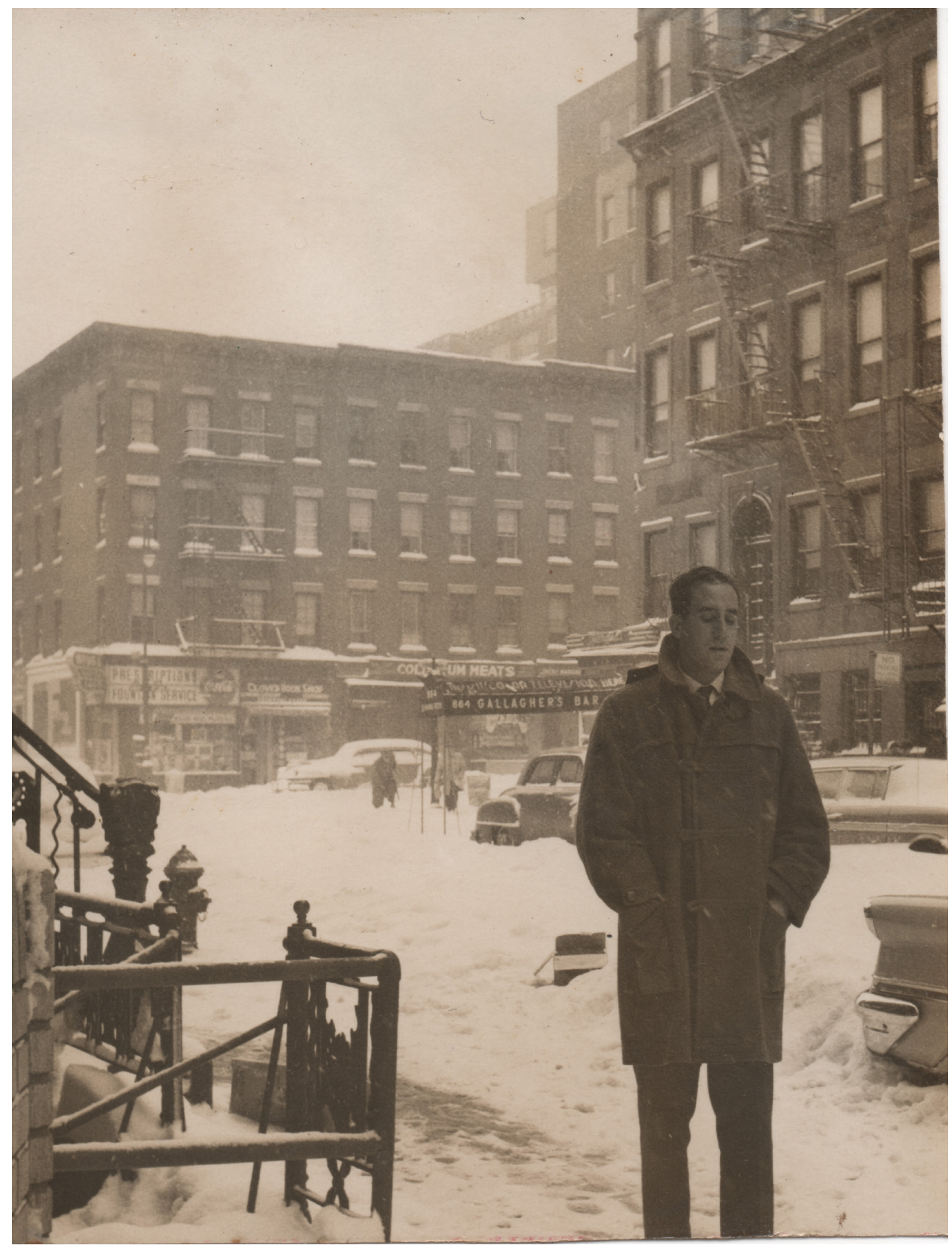

Néstor Almendros en Nueva York, invierno de 1958. 


\section{Introducción}

[2] Néstor Almendros, Cinemanía (Barcelona, Seix Barral, 1992), p. 7; la versión en castellano de Días de una cámara, cuya primera edición salió en francés (Un homme à la caméra, Lausanne, FOMA 5 Continents, 1980), la publicó Seix Barral en Barcelona en 1982; usamos aquí la reedición ampliada de febrero de 1993.

[3] Tras su fallecimiento, se publicaron en nuestro país tres pequeños libros sobre Almendros, de carácter colectivo y muy valiosos, pero sin ánimo de exhaustividad (ninguno supera, de hecho, las 75 páginas): nos referimos a Pere Gimferrer et al., Néstor Almendros (Barcelona, Filmoteca de Catalunya, 1993); Antonio Gosálvez, Néstor Almendros en Sevilla (Sevilla, Filmoteca de Andalucía, 1999); y Juan A. Castaño et al., Néstor Almendros (Las Palmas, Cuadernos de Filmoteca Canaria, 2003).

[4] Como director de fotografía, Almendros solo filmó un largometraje «español», Cambio de sexo (Vicente Aranda, 1976), y el cortometraje documental $\mathrm{La}$ Asamblea de Catalunya (Carles Durán, 1981), aunque rodó partes de More (Barbet Schroeder, 1969) en Ibiza y dirigió su cortometraje El bastón (1970), de producción francesa, en Barcelona; para sus otros dos proyectos frustrados de rodaje en Cataluña, con Jordi Grau y Glauber Rocha, así como su relación con la Escuela de Barcelona, véase R. Gubern, «Herida abierta», en Néstor Almendros (2003), pp. 7-9.

[5] Entre los textos más recientes que trazan un perfil de toda su carrera, destacan Lluís Cerarols, «Néstor Almendros: Biografia d'un home de cinema» (Modilianum, $\mathrm{n} .{ }^{\circ} 35$, segundo semestre de 2006), pp. 33-50, y Dunia Gras, «Introducción», en El arte de la nostalgia: Cartas de Néstor Almendros a Guillermo Cabrera Infante (Madrid, Verbum, 2013), pp. 9-35, que comenta la desaparición del archivo de Almendros en p. 11.
Un estudio pormenorizado de la obra del cineasta catalán Néstor Almendros (Barcelona, 1930-Nueva York, 1992) revela dos facetas fundamentales de su trayectoria que, a día de hoy, apenas han sido estudiadas: la de crítico cinematográfico y la de director de cine experimental y documental. La fama de Almendros como director de fotografía - por su colaboración con directores como François Truffaut y Martin Scorsese y la obtención de un Óscar por Días de cielo (Days of Heaven, 1978) de Terrence Malick - ha eclipsado estas otras dos prácticas profesionales de su carrera, que a menudo fueron paralelas a su trabajo de camarógrafo e incluso, en algunas etapas de su vida, prioritarias. Como señaló el propio Almendros en el prólogo a su libro Cinemanía en 1992: «Al publicarse mi primer libro Días de una cámara, algunas personas debieron de preguntarse: ¿cómo un director de fotografía se atreve a escribir un libro sin ser un profesional de la escritura? En realidad, debieron haberse invertido los términos de la pregunta: ¿cómo un crítico de cine se atrevió a convertirse en director de fotografía?». ${ }^{2}$ Entre 1956 y 1964, en efecto, Almendros publicó decenas de críticas cinematográficas en numerosas revistas americanas y europeas. Por otro lado, un rápido recuento de su filmografía como director asciende a nada menos que 25 títulos realizados en Cuba, Estados Unidos, Francia y España entre 1951 y 1988.

Aunque se han publicado en nuestro país algunos textos breves que mencionan ambas facetas, la de crítico y director de cine, lo cierto es que la trayectoria de Almendros, en toda su complejidad y relevancia, sigue siendo prácticamente desconocida a casi treinta años de su muerte. ${ }^{3}$ Este desconocimiento se debe principalmente a tres factores de distinta naturaleza. El primer factor, de recepción, tiene que ver con un malentendido generalizado, el de pensar que sus dos libros de cine -Días de una cámara (1982) y Cinemanía (1992) - dan cuenta cabal de su vida y abarcan la totalidad de su obra, cuando en realidad, tras una consulta contrastada de fuentes, solo cubren una parte limitada de la misma. Aunque Días de una cámara contiene algunos esenciales apuntes biográficos, es principalmente un libro técnico (escrito para futuros directores de fotografía), y Cinemanía reúne menos de la mitad de los artículos que Almendros publicó en vida (y ninguna de las varias docenas de entrevistas que le fueron realizadas a partir de 1970). Son, sin duda, dos libros imprescindibles, pero que, como es natural, también han dejado tras de sí no pocas pistas falsas. El segundo factor es el hecho de que Almendros desarrolló su obra casi por completo en el exilio (cubano, estadounidense, francés), lo cual ha ubicado su trabajo en esa tierra de nadie, el cine de la diáspora española, que sigue siendo una asignatura pendiente de los historiadores de nuestro cine. ${ }^{4}$ El tercer y último factor ha sido la desaparición del archivo personal de Almendros tras su fallecimiento en marzo de 1992, algo que ha dificultado muy considerablemente la labor de aquellos que se han aproximado a su trayectoria. ${ }^{5}$ Una parte no desdeñable de sus películas como director, de hecho, se encuentra perdida o en archivos fílmicos, en copia única, a la espera de su digitalización.

Pero estos obstáculos no deberían desalentar al investigador: importantes materiales de archivo de Almendros pueden encontrarse en las colecciones de otros cineastas con los que colaboró estrechamente (por ejemplo, el Fonds François Truffaut de la Cinémathèque française de París y el Fonds Éric Rohmer del IMEC en Caen); un número considerable de sus películas está siendo digitalizado por diversas filmotecas internacionales (nos referimos en concreto a sus films realizados para la televisión francesa entre 1965 y 1968, accesibles hoy en el Réseau Canopé de Poitiers); práctica- 
mente todas las entrevistas y textos no recogidos en Cinemanía se pueden encontrar en hemerotecas y bibliotecas especializadas; y el nuevo trabajo de algunos investigadores sobre otras figuras del cine español en el exilio (en Marruecos, Francia, México) está contribuyendo a esclarecer la idiosincrasia del cine español de la diáspora. ${ }^{6}$ Por estas razones, una reconstrucción «completa» de la vida y obra de Almendros empieza a ser posible.

Este artículo, que forma parte de una investigación más amplia con dicho objetivo (la publicación de la primera biografía crítica del cineasta catalán), se centra en el período que Almendros pasó en Nueva York entre agosto de 1957 y agosto de 1959. Es una etapa en la que desarrolló su carrera como hispanista y director escénico (para Vassar y Middlebury College), como comisario y crítico de cine (para el cineclub de Vassar College y la revista Film Culture) y en la que dirigió dos de sus primeros films experimentales, The Mount of Luna (El monte de la luna, 1958) y 58-59 (1959), ambos rodados en blanco y negro, en $16 \mathrm{~mm}$, en el corazón mismo de Manhattan. Refugiado de la España franquista en Cuba en 1948 y de la Cuba batistiana en Estados Unidos en 1955, Almendros cursó estudios de cine en el Institute of Film Techniques del City College de Nueva York, dirigido por Hans Richter, en otoño de 1955. Vivió una temporada en Los Ángeles en la primavera de 1956 y, tras pasar por Ciudad de México en verano de 1956, estudió el año académico 1956-1957 en el Centro Sperimentale di Cinematografía de Roma. Fue esta segunda etapa en Nueva York, al cierre de la década de 1950, la que marcó el final de sus años de formación e inauguró su carrera profesional como cineasta internacional. ${ }^{7}$

\section{Hispanismo y dirección escénica}

Almendros llegó al puerto de Nueva York desde Le Havre a finales de agosto de 1957 y desde allí tomó el tren a Poughkeepsie, una villa situada a orillas del Hudson, donde se ubica Vassar College, a 110 kilómetros al norte de Manhattan. ${ }^{8}$ Unos meses antes, había conseguido el trabajo de lector en el Departamento de Español de dicha universidad probablemente por mediación de la profesora cubana Camila Henríquez-Ureña, hija de un antiguo presidente de la República Dominicana y fundadora del Lyceum de La Habana. El catalán había publicado un artículo para la revista del Lyceum en $1954^{9} \mathrm{y}$, tras solicitar el trabajo a través de un amigo de su familia, tuvo la «tremenda suerte» (en palabras de su padre, Herminio Almendros) ${ }^{10}$ de ser seleccionado para dicho trabajo.

Fundada en 1861 por el filántropo Matthew Vassar a imagen y semejanza del tradicional college británico, Vassar era - y es - una de las siete universidades que conforman la prestigiosa liga de las Seven Sisters o Siete Escuelas Hermanas (una suerte de Ivy League femenina). Por sus aulas habían pasado, entre otras, las escritoras Elizabeth Bishop y Mary McCarthy y, en los dos cursos que Almendros estaría en el college, visitarían el campus conferenciantes como W. H. Auden, Vladimir Nabokov y Robert Oppenheimer.

¿Quién conformaba por entonces el Departamento de Español de Vassar? La catedrática y jefa del departamento era doña Pilar de Madariaga, intelectual republicana y hermana del célebre diplomático Salvador de Madariaga; HenríquezUreña era profesora titular; en calidad de profesores asociados ejercían la docencia la viguesa Sofía Novoa, también republicana exiliada, y Carlos Hamilton, un chileno, hijo de británico, que venía de impartir clases en la Universidad de Columbia. Como
[6] Para una amplia bibliografía, un análisis del estado de la cuestión y una primera aproximación a nuevas vías de investigación sobre cine español y exilio, veáse Juan Rodríguez, «Los exiliados republicanos y el cine (una reflexión historiográfica)», Iberoamericana (vol. XII, n. ${ }^{\circ} 47,2012$ ), pp. 157168.

[7] Sus impresiones sobre su formación se resumen en Días de una cámara, pp. 38-39.

[8] Gran parte de la reconstrucción del período de Almendros en Vassar College es posible gracias a la documentación albergada en los archivos y hemeroteca del centro: la carpeta «Néstor Almendros» (que incluye un «Bio File» fechado en 1958), la descripción de cursos en los boletines anuales y las noticias en las que se le menciona en los dos periódicos universitarios, The Miscellany News y The Vassar Chronicle; véase también M. Bruno y E. A. Daniels, Vassar College (Charleston, Arcadia, 2001).

[9] «Bio file», Special Collections, Vassar College, p. 6.

[10] «Resulta que [Néstor] ha tenido una tremenda suerte. Alguien amigo de él y nuestro le avisó y propuso y apoyó que solicitase una vacante de instructor de español en Vassar College», carta de Herminio Almendros a Josep Ferrater Mora, 4 de julio de 1957, Fons Ferrater Mora, Universitat de Girona. 
[11] Hemos traducido así los términos anglosajones de Chairman (jefe de departamento), Professor (profesora titular), Associate Professors (profesores asociados) e Instructor (lector), aun siendo conscientes de que dichas equivalencias no son del todo exactas, dado que ambos sistemas académicos tienen tipos de contratación diferentes.

[12] «Guillén Discusses Jiménez's Poetry» (Vassar Miscellany News, vol. XXXXII, n. ${ }^{\circ} 2,25$ de septiembre de 1957), p. 3 у p. 6.

[13] «38 Members Added To Vassar Faculty» (Vassar Miscellany News, vol. XXXXII, n. ${ }^{\circ} 2,25$ de septiembre de 1957), p. 3 y 6.

[14] Vassar College Course Catalogue 1957-1958, p. 132; su salario era de 500 dólares al mes.

[15] N. Almendros, «Estudio fonético del español en Cuba (región occidental)» (Boletín de la Academia Cubana de la Lengua, vol. II, n. ${ }^{\circ} 1-2$, enero-junio de 1958), pp. 138-176. lectora, la cubana Rosa Whitmarsh dejaba la plaza vacante que a partir de ahora ocuparía Almendros a tiempo completo. ${ }^{11}$ El catalán se encontraba, pues, en un ambiente internacional fuertemente vinculado al exilio español y a la cultura cubana, es decir, en un contexto muy familiar. El departamento tenía además conexión con otras figuras claves de la Generación del 27 en el exilio, como Pedro Salinas o Jorge Guillén, quien, sin ir más lejos, había impartido allí una charla sobre la poesía de Juan Ramón Jiménez en abril de $1957 .{ }^{12}$

A comienzos de septiembre, Almendros fue presentado oficialmente junto a otros 37 nuevos profesores. ${ }^{13}$ Por el boletín del curso 1957-1958, sabemos que impartió la asignatura de «Elementary Spanish» (Español elemental) en tres sesiones de una hora, cuatro mañanas a la semana, enfocado en la enseñanza de la «gramática y lectura de textos modernos con especial énfasis en la conversación y la redacción». ${ }^{14}$ Es muy probable que, en tanto lector (ese año y el próximo curso 1958-1959), Almendros también diese algunas clases de los cursos «Composition and Conversation» (Composición y conversación) y «Study of Language through Representative Works» (Estudio del idioma a través de obras representativas), donde se estudiaban todos los años diversos textos de autores contemporáneos en lengua española. Las clases eran de grupos reducidos y se impartían en inglés y castellano.

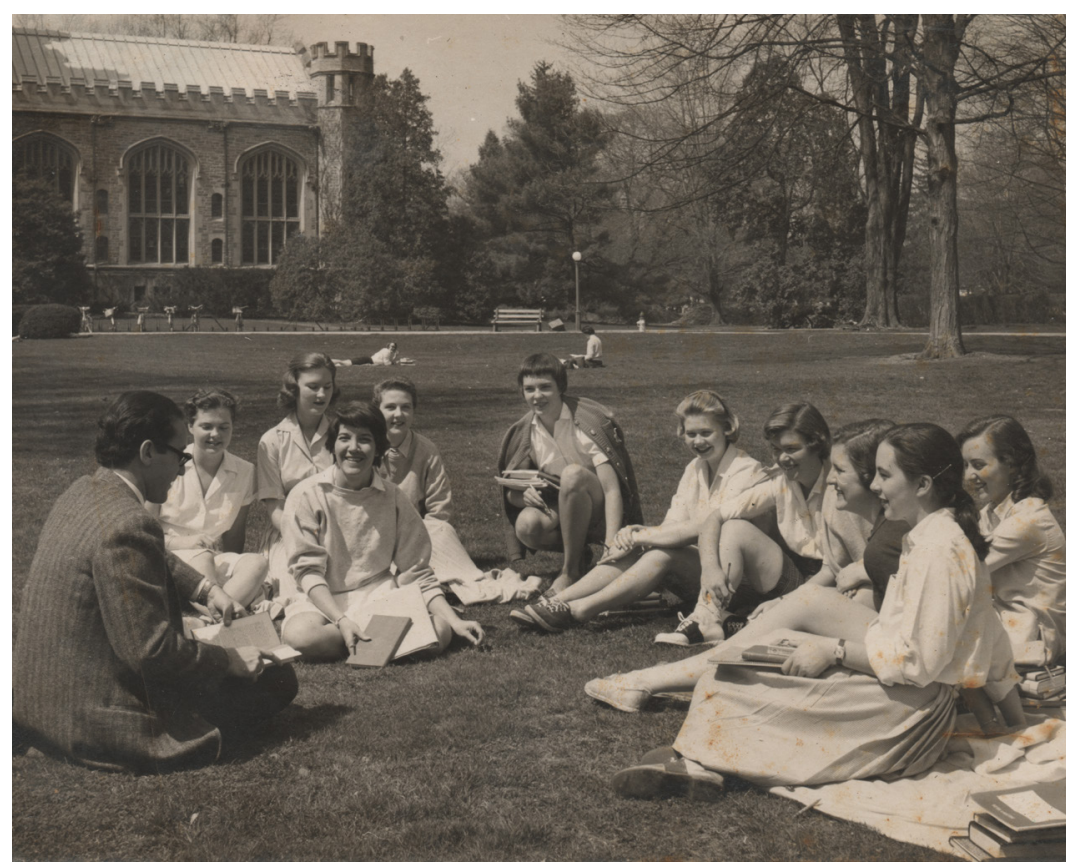

Almendros con un grupo de alumnas, Vassar College, Poughkeepsie, otoño de 1957.

Como parte de su actividad como hispanista, Almendros recibió al poco de llegar a Vassar la publicación de su tesis de licenciatura en La Habana, «Estudio fonético del español en Cuba», por el Boletín de la Academia Cubana de la Lengua,$^{15}$ donde estudiaba las variantes del castellano de la isla y hacía especial énfasis en las alteraciones cubana y afrocubana del idioma. Un álbum personal de Almendros guarda algunas instantáneas de su vida en Vassar: en una fotografía aparece impartiendo docencia sobre el césped ante un animado grupo de alumnas; en otra, trabajando en su cuarto, 
ubicado en la Kendrick House y decorado con reproducciones de dibujos renacentistas; y aun en otra, en esa misma habitación, apoyado en la repisa de la chimenea, rodeado de fotos, mapas de ciudades europeas y un elocuente cartel de un viejo cine italiano que se había traído de Roma en 1957 («Durante los 30 minutos de la famosa secuencia muda se suspende el acceso a la sala: prohibido a menores de 16 años»). ${ }^{16}$

La proximidad de Vassar a Nueva York permitió a Almendros visitar la ciudad a menudo. Allí trabajaba su hermana María Rosa, que se había casado con el escritor cubano Edmundo Desnoes - más adelante, co-guionista de Memorias del subdesarrollo (1968) de Tomás Gutiérrez Alea-y juntos vivían en Manhattan, en el apartamento 1A del número 352 de la Calle 56 Oeste. Como indicó años más tarde María Rosa,

[Néstor] nos visitaba los fines de semana. Mi casa consistía en una gran sala, dividida por un biombo. Detrás, se hallaba «la oficina» de Edmundo. Una decoradora rica que conocimos por casualidad, nos regaló una alfombra blanca y nos descalzábamos para pisarla. Había un sofá (donde dormíamos), un librero y una caja de municiones del ejército. ¡Ah!, también la tripa de un televisor que, al venir sin mueble, costó poco. A pesar de eso, se veía... ${ }^{17}$

Desnoes trabajaba por entonces para Visión, una revista quincenal en español con sede en Madison Avenue, en la que Almendros publicaría alguna fotografía ${ }^{18}$ y con la que también colaboraban por entonces otros cubanos exiliados de la dictadura de Batista, como el fotorreportero Jesse Fernández y el escritor Humberto Arenal. ${ }^{19}$

Además de las clases y publicaciones en el ámbito del hispanismo, Almendros desarrolló una intensa actividad como director escénico. A través de Francisco García Lorca, hermano del poeta, había entrado en contacto con la prestigiosa Escuela de Idiomas del Middlebury College en Vermont. Francisco era profesor asociado en la Universidad de Columbia y visitó Vassar para impartir una conferencia sobre un poema de Federico, «La monja gitana», el 23 de abril de $1958 .{ }^{20}$ Suponemos que fue él quien, al enterarse que la Escuela de Idiomas — de la que era co-director- necesitaba a alguien que pusiera en escena algunas piezas teatrales en castellano, recomendó a Almendros. En cualquier caso, fuera quien fuese, el 31 de marzo Néstor recibió una carta de Stephen Freeman, vicerrector de Middlebury, invitándolo a formar parte del programa de verano, ${ }^{21}$ a la que Almendros respondía unos días después: «Estoy convencido de que pasaré un verano feliz y placentero con ustedes». ${ }^{22}$

Middlebury se encuentra en una apartada región de lagos y montañas en el condado de Addison, cerca de Canadá. Al igual que Poughkeepsie, es un pequeño pueblo conocido principalmente por su campus universitario. La sección española de la Escuela de Idiomas de la universidad, fundada en 1917 y co-dirigida aquel verano por el cervantista Joaquín Casalduero, había venido convocando a parte de la élite cultural hispanohablante de la época en Estados Unidos. En sus aulas se habían reunido intelectuales de la talla de Ramiro de Maeztu, Concha Espina, Amado Alonso, Gabriela Mistral, Salinas, Luis Cernuda, Américo Castro, Fernando de los Ríos, Humberto Piñera, Luis Quintanilla, Eugenio Granell, Octavio Paz, Claudio Guillén... ${ }^{23}$

Almendros llegó a Middlebury a finales de junio y se alojó en la habitación 305 del Starr Building. Contratado en calidad de «Auxiliary Personnel in Charge of the Theatre» (Personal auxiliar a cargo del teatro) con un salario de 275 dólares, alojamiento y manutención, puso en escena tres piezas dramáticas, contando con la interpretación de profesores y alumnos. ${ }^{24}$ La primera de ellas fue Sancho Panza en la
[16] Archivos de Belén Piqueras, Almansa.

[17] E. Mirabal y C. Velazco, «María Rosa mira los Almendros» (Revolución y cultura, época $\mathrm{V}, \mathrm{n}$. ${ }^{\circ}$ 4, octubre-diciembre de 2019), p. 26.

[18] Por ejemplo, el retrato fotográfico de Ferrater Mora en E. Denoes, «Ferrater, en inglés» ( $\mathrm{Vi}$ sión, vol. 15, n. ${ }^{\circ} 4,20$ de junio de 1958), pp. 70-71; véase también al respecto la carta de N. Almendros a J. Ferrater Mora, 21 de abril de 1958, Fons Ferrater Mora.

[19] A partir de enero de 1958 también se trasladó a Nueva York el hermano menor de Almendros, Sergio, que cursó allí estudios de litografía, tal y como se informa en carta de H. Almendros a Ferrater Mora, 23 de marzo de 1958, Fons Ferrater Mora.

[20] «Francisco Lorca Talks about Brother's Work» (Vassar Chronicle, vol. XV, n. ${ }^{\circ} 23,19$ de abril de 1958), p. 1.

[21] Carta de S. Freeman a NA, 31 marzo de 1958, Special Collections, Middlebury College.

[22] Carta de N. Almendros a S. Freeman, 10 de abril de 1958, Special Collections, Middlebury College.

[23] Cfr. S. Freeman, The Middlebury College Foreign Language Schools, 1915-1970: The Story of a Unique Idea (Middlebury: Middlebury College Press, 1975), p. 338; además del libro de Freeman, hemos consultado los boletines de la escuela de los veranos de 1958, 1959 y 1960, así como los «Records of the Director of the Summer Programs», Special Collections, Middlebury College.

[24] Summer Language Schools: Middlebury College Bulletin (marzo de 1958), p. 55. 


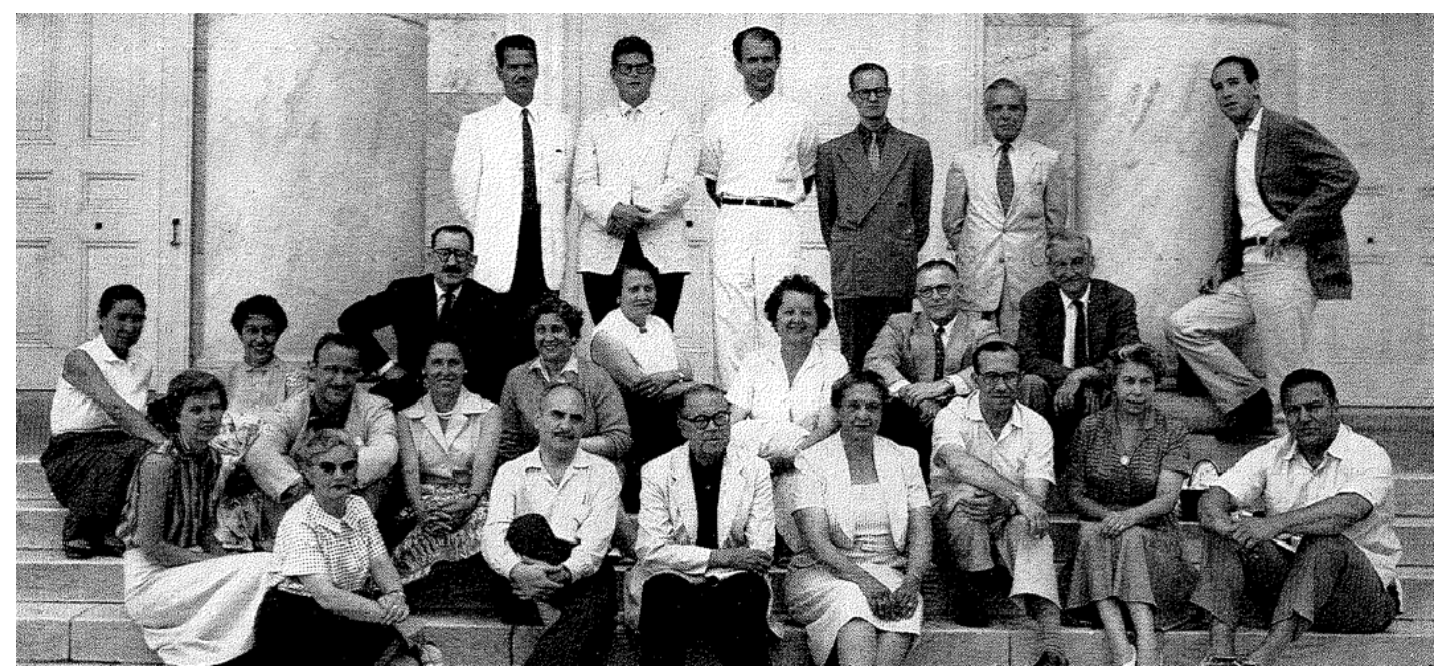

Almendros, en pie a la derecha, junto al profesorado de la Escuela de Idiomas del Middlebury College, julio de 1958; en primera fila, sentados, María de Unamuno (con gafas de sol), Francisco Ayala, Joaquín Casalduero y Camila Henríquez-Ureña.

insula Barataria, una obra que Alejandro Casona había escrito para el Teatro del Pueblo de las Misiones Pedagógicas promovidas por el gobierno de la Segunda República a mediados de la década de 1930. Para ello, Almendros trabajó con los actores Manuel Asensio (un granadino exiliado que daba clases en Haverford College), Deane Conklin y Elizabeth Young, entre otros. Al tener un vínculo estrecho con Casona (amigo íntimo de su padre Herminio), Almendros era la persona idónea para dirigir esta farsa en un acto basada en un episodio de El Quijote, aquel en que Sancho cumple su sueño de ser gobernador. Tras varias semanas de ensayos, la obra se estrenó con éxito en el Wright Memorial Theater, un pequeño teatro de estilo neoclásico recién inaugurado en el centro del campus. Se ha conservado una imagen de la función que muestra la calidad de la escenografía. ${ }^{25}$ Junto a esta pieza, Almendros también dirigió Rosina es frágil (1918) de Gregorio Martínez Sierra y Amor de don Perlimplín con Belisa en su jardin (1933) de García Lorca, ambas estrenadas el viernes 1 de agosto en aquel mismo teatro.

La fotografía que nos queda del cuerpo docente (¿tomada quizá por el propio

[25] Ibid., p. 64; el presupuesto de la producción fue de 400 dólares.

[26] La fotografía aparece publicada en Summer Language Schools: Middlebury College Bulletin (marzo de 1959), p. 54.

[27] F. Ayala, «Generalidades con pretexto de un libro de Eisenstein», en El cine, arte y espectáculo (Buenos Aires, Argos, 1949), pp. 173-178.

[28] «Dr José Arrom Keynotes Festival» (Vassar Chronicle, vol. XVI, n. ${ }^{\circ} 16,7$ de febrero de 1959), p. 1. catalán con el disparador automático de su cámara?) muestra a los profesores en la escalinata de una facultad y a Almendros, con americana, apoyado sobre una columna de la fachada. ${ }^{26}$ Sentados en primera fila aparecen también la hispanista María de Unamuno, hija del filósofo, y el escritor Francisco Ayala, por entonces director de publicaciones de la Universidad de Puerto Rico y autor de libro El cine, arte y espectáculo (1949), cuyo capítulo sobre Eisenstein, Almendros debió leer por aquella época. ${ }^{27}$

De regreso a Vassar, el catalán continuó con su actividad teatral. En febrero de 1959, puso en escena El entremés del mancebo que casó con mujer brava, uno de los cuentos medievales de El conde Lucanor (1335) de Don Juan Manuel, también adaptado por Casona antes de la Guerra Civil. Se encargó de la coreografía Sofía Novoa y la función fue, según la prensa, «ingeniosa y encantadora». ${ }^{28}$ Dos fotografías publicadas en la revista de alumnos reproducen imágenes de la representación y la danza que incluía. Como las producciones teatrales en Middlebury habían sido «especialmente exitosas» ${ }^{29}$, en mayo 
de 1959 la Escuela de Idiomas volvió a contratar a Almendros en unas condiciones similares a las del año anterior. ${ }^{30}$ Allí pasó mes y medio, del 26 de junio al 13 de agosto de 1959, y puso en escena El retablo del Maese Pedro (1923) de Manuel de Falla, el 31 de julio, y La malquerida (1913) de Jacinto Benavente, el 4 de agosto; ambas, de nuevo, en el Wright Theater. ${ }^{31}$ Difícil obviar las conexiones cinematográficas de ambas piezas: El retablo del Maese Pedro, obra musical para títeres, fue la primera experiencia escénica de Buñuel, allá por 1926, y La malquerida, el drama rural de Benavente, fue adaptada al cine por José López Rubio en España en 1940 y por el Indio Fernández en México en 1949, con Dolores del Río y Pedro Armendáriz en los papeles protagonistas. Sin duda, el cinéfilo Almendros era consciente de ambas conexiones.

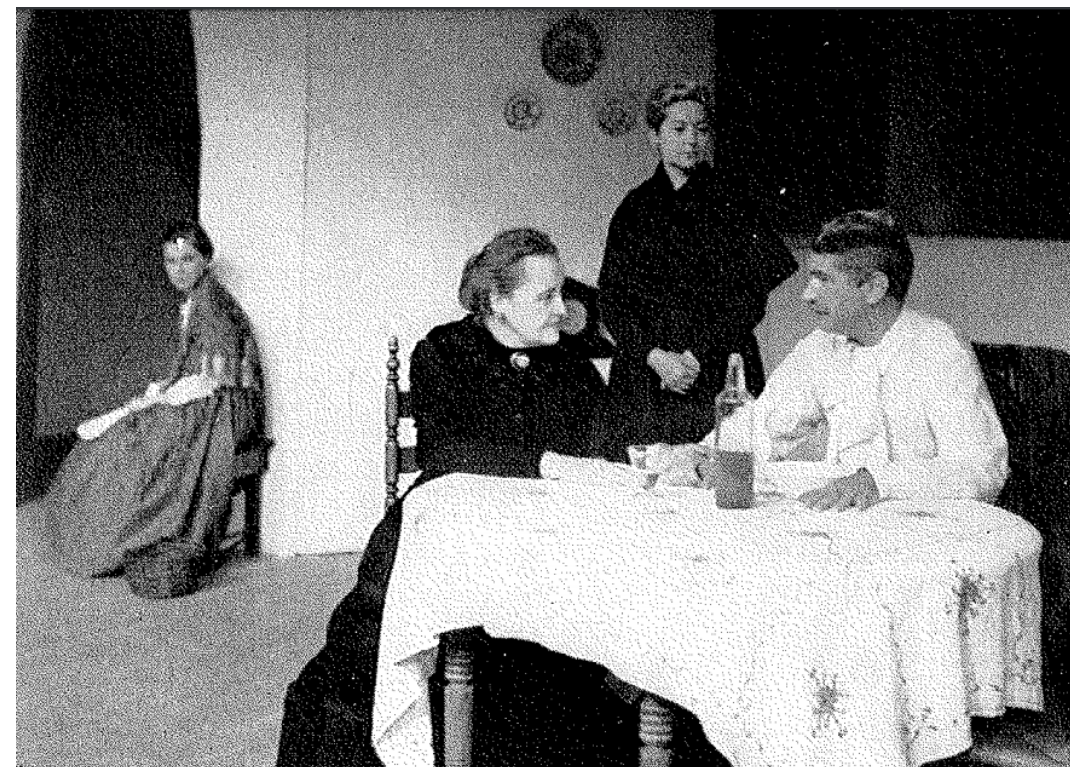

Representación teatral de La malquerida dirigida por Almendros, Wright Theater, agosto de 1959.

\section{Cine-clubismo en Vassar y Middlebury}

La actividad de Almendros como comisario de cine empezó al poco de llegar a Vassar. Ya en otoño de 1957 se reunió con un grupo de docentes y estudiantes con el objetivo de fundar The Film Committee (también llamado The Film Group), organismo a cargo de gestionar el primer cineclub en la historia de la universidad. La formación del grupo fue, como dirían sus miembros más tarde, «completamente espontánea, ya que surgió de la motivación sincera de un grupo de personas interesadas en organizar un club que permitiese ver, estudiar y comentar algunas de las mejores películas de la historia». ${ }^{32}$ La inauguración del cineclub propiamente dicha tuvo lugar unos meses más tarde: tal y como informaba el Vassar Chronicle el 15 de febrero de 1958,

El primer ciclo de películas, que se proyectará los viernes por las noches durante el cuatrimestre de primavera, se titula «Great Stars of the Twenties» [Grandes estrellas de los años veinte]. Incluirá películas mudas y sonoras. Tras cada proyección, se organizará un debate moderado por miembros del club. El primer encuentro tendrá lugar dentro de dos semanas. ${ }^{33}$
[29] J. Casalduero, «Report of the Director. Spanish School 1958» [1958], p. 1, Special Collections, Middlebury College.

[30] Carta de S. Freeman a NA, 26 de mayo de 1959 , Special Collections, Middlebury College; esta vez el salario era de 300 dólares.

[31] Hay fotografía de la función de La malquerida en Summer Language Schools: Middlebury College Bulletin (marzo de 1960), p. 61 .

[32] «Letter to the Editor» (Vassar Miscellany News, vol. XXXXIII, n. ${ }^{\circ} 14,14$ de enero de 1959), p. 2.

[33] Film Club Forms Group with Faculty» (Vassar Chronicle, vol. XV, n. ${ }^{\circ} 16,15$ de febrero de 1958), p. 1. 
[34] «Film Club Gives First Movie In Series» (Vassar Miscellany News, vol. XXXXII, n. ${ }^{\circ} 22,16$ de abril de 1958), p. 1; no se conserva copia de dicha charla, pero Almendros comenta con detalle la secuencia de los bloques de hielo en el documental Visions of Light (1993) de Arnold Glassman, Todd McCarthy y Stuart Samuels.

[35] N. Almendros et al., «Letter to the Editor» (Vassar Miscellany News, vol. XXXXIII, n. ${ }^{\circ} 14,14$ de enero de 1959), p. 2.

[36] Andrew Sarris, «Notes on Author Theory in 1962» (Film Culture, . $^{\circ} 27$, invierno de $1962-$ $63)$, pp. 1-8, y «The American Cinema» (Film Culture, n. ${ }^{\circ} 28$, primavera de 1963), pp. 1-51.

Además de Almendros, conformaban The Film Club, entre los profesores, Mario Domandi del Departamento de Italiano y John Murra del Departamento de Antropología, y entre las alumnas, Hetty Albo, Marilyn Galusha y Lucia Robinson. La primera proyección tuvo lugar el 11 de abril de 1958, a las 7:45pm, en el escalonado anfiteatro de la universidad, el Blodgett Auditorium. Se pasó el drama Las dos tormentas (Way Down East, 1920), de D. W. Griffith, fotografiado por Billy Bitzer y con Lillian Gish en el papel protagonista, célebre por la secuencia en la que Gish salta entre bloques de hielo en la escena culminante del film. Tras la proyección, Almendros impartió la charla «The Twenties' Films in relation to the Development of the Star System» (El cine de los años veinte en relación al desarrollo del star system). ${ }^{34}$ A Las dos tormentas siguieron, las semanas siguientes, Corazón olvidado (Blind Husbands, 1919) de Erich von Stroheim con Gibson Gowland; Robin de los Bosques (Robin Hood, 1922) de Allan Dwan con Douglas Fairbanks; Sangre y arena (Blood and Sand, 1922) de Fred Niblo con Rodolfo Valentino; La leyenda de Gösta Berling (The Saga of Gösta Berling, 1924) de Mauritz Stiller con Greta Garbo; y, en última sesión, la sensual Marruecos (Morocco, 1930) de Josef von Sternberg, con Gary Cooper y Marlene Dietrich. Conociendo los gustos cinéfilos de Almendros, puede observarse claramente su participación en la selección de títulos del ciclo.

$\mathrm{Al}$ no disponer Vassar de un proyector de $35 \mathrm{~mm}$, las

V.C. Film Club Gives First Movie In Series

The first in a series of six films designed to illustrate the growth of the star system in the twenties was shown Friday evening. April 11. An activity of the newly organized Student - Faculty Film Club, which endeavors to stress the cinema as a significant art form and to discuss its evolution, its special problems and its outstanding results, the series is shown in Blodgett Auditorium on Fridays at $7: 45$ p.m.

A brief introduction identifying the artistic and historical context of each film will orecede all showings, and a discussion led by either faculty or students will follow. Last Friday's movie "Way Down East" (1920), starring Lillian Gish, followed a lecture on April 9 by Mr. Nestor Almendros of the Spanish department, who discussed the series of twenties films in relation to the development of the star system.

Vassar Miscellany News, 16 de abril de 1958. cintas se pasaron en $16 \mathrm{~mm}$. Aunque la entrada era gratuita, a aquel primer ciclo no asistió tanto público como se esperaba, lo que causó cierta sensación de malestar entre los miembros más entusiastas del cineclub. Además, durante el pase de Sangre y arena, unos espectadores boicotearon la sesión burlándose de la ingenuidad de ciertos subtítulos y de los gestos de los actores, abandonando la sala en medio de la proyección. ${ }^{35}$ Pequeñeces que los cinemaníacos de entonces no se tomaban a la ligera.

El segundo ciclo, «The Development of the Western» (La evolución del Western), empezó el 3 de octubre de 1958. Al igual que el programa anterior sobre el star system, presentaba un enfoque todavía no dominado por la incipiente teoría del autor (iba a ser precisamente en las páginas de Film Culture, con un par de artículos de Andrew Sarris, donde se popularizaría la politique des auteurs en Estados Unidos). ${ }^{36}$ Para el ciclo, Almendros y sus colegas obtuvieron copias de la filmoteca del Museo de Arte Moderno de Nueva York y llegaron a un acuerdo con el cine Juliet -la sala de Poughkeepsie, ubicada en Raymond Avenue- para mostrar títulos también en $35 \mathrm{~mm}$. En la primera velada proyectaron nada menos que Asalto y robo de un tren (The Great Train Robbery, 1903) de Edwin S. Porter, a la que siguieron, durante las semanas siguientes, The Last Card (La última carta, 1915) de William S. Hart y El caballo de hierro (The Iron Horse, 1924) de John Ford, entre otras. Se trataba de demostrar, por un lado, que el cine del Oeste era un 
«arte cinematográfico puro», ${ }^{37}$ con énfasis especial en su génesis durante el período mudo, y, por otro, que sus convenciones genéricas y estéticas no se limitaban solamente al ámbito estadounidense: el ciclo, de hecho, incluyó clásicos del cine mundial, como la soviética Tempestad sobre Asia (Potomok Chingiskhana, 1927) de Vsevolod Pudovkin, la brasileña $O$ Cangaceiro (1953) de Lima Barrero y la japonesa Los siete samuráis (Sichinin no samurai, 1954) de Akira Kurosawa, cuyas proyecciones —esta vez sí- fueron muy exitosas. ${ }^{38}$

En primavera de 1959, habiéndose ganado ya la aceptación popular del alumnado, los miembros del cineclub exigían ahora en el periódico de la universidad una mayor atención por parte del equipo rectoral. «Nos ha sorprendido la falta de interés o incluso curiosidad por lo que hacemos», reclamaban Almendros y sus colegas en una carta del 14 de enero al editor del Vassar Miscellany News:

Y no es que seamos un grupo dedicado a una tarea esotérica u obscura: el cine, después de todo, es el único arte nacido en el siglo XX. Es una pena que, pasada casi una década de la mitad del siglo, exista una institución académica que, comparativamente, muestre tan poco interés por una forma artística tan joven y fascinante. ${ }^{39}$

Del 14 de marzo al 8 de mayo de 1959 tuvo lugar el tercer ciclo, el de cine experimental, de excepcional calidad, y el último co-comisariado por Almendros. Además de incluir Viaje a la luna (Le Voyage dans la lune, 1902) de Georges Méliès y varios cortometrajes de Chaplin, pasaron algunos títulos fundamentales del cine de vanguardia de entreguerras como, por ejemplo, Nosferatu (1922) y El último (Der letzte Mann, 1924) de Murnau; varios noticiarios del Kino-Pravda (Cine-Verdad, 1922) de Dziga Vertov y El acorazado Potemkin (Bronenosets Potyomkin, 1925) de Eisenstein; el Ballet mécanique (Ballet mecánico, 1924) de Fernand Léger y Dudley Murphy, L'Étoile de mer (La estrella de mar, 1928) de Man Ray y Un perro andaluz (Un Chien andalou, 1929) de Luis Buñuel. ${ }^{40}$ Almendros presentó personalmente algunas de las proyecciones, quizá incluso la que se hizo del Orfeo (Orphée, 1951) de Cocteau, en $35 \mathrm{~mm}$, en el Juliet. La última sesión, a principios de mayo, se centró en cine experimental americano contemporáneo: se proyectaron para la ocasión varios cortometrajes del animador escocés-canadiense Norman McLaren y de la directora ruso-americana Maya Deren, quien, de hecho, visitó Vassar con motivo de dicha ocasión ${ }^{41}$.

Recordando aquella visita en Días de una cámara, Almendros diría: «Yo había trabado buena amistad con la cineasta experimental Maya Deren, una artista sin contaminación comercial alguna y que influyó mucho en mi carrera». ${ }^{42}$ En nombre del Film Group, el catalán la convidó a dar una charla en la universidad el 7 de mayo de 1959: «Invité a Deren al cine-club. [...] Era maravillosa, más como persona que como artista. Era alguien a quien el movimiento underground americano debía mucho, una especie de éminence grise. Estuvo detrás de tantas iniciativas y tenía tanto entusiasmo. Y a mí me pasó ese tipo de entusiasmo. Sus ideas eran estupendas, mejor incluso que sus películas. Era realmente fantástico escucharla hablar del arte cinematográfico»». ${ }^{43}$ La conferencia de Deren en el Blodgett Auditorium incluyó la proyección de tres películas suyas, posiblemente Meshes of the Afternooon (Las redes de la tarde, 1943), Ritual in Transfigured Time (Rito en el tiempo transfigurado, 1946) y Meditation on Violence (Meditación sobre la violencia, 1948). ${ }^{44}$ Desafortunadamente, no se conserva ninguna fotografía de Almendros con la cineasta experimental, pero sus primeros cortometrajes de vanguardia en Nueva York (y en La Habana a partir de su regreso
[37] Mary Davis, «Film Club Announces Series of "Westerns"» (Vassar Miscellany News, vol. XXXXIII, n. ${ }^{\circ}$, 1 de octubre de 1958), p. 1.

[38] «Film Club Schedules Series On Westerns» (Vassar Chronicle, vol. XVI, n. ${ }^{\circ}$ 2, 27 de septiembre de 1958), p. 1 y 4.

[39] «Letter to the Editor» (Vassar Miscellany News, vol. XXXXIII, n. ${ }^{\circ} 14,14$ de enero de 1959), p. 2.

[40] «Chaplin, Vertov Included in Film Club Program» (Vassar Miscellany News, vol. XXXXIV, Freshmen Issue, 16 de marzo de 1959), p. 5.

[41] «Film Club Introduces Experimental Cinema» (Vassar Chronicle, vol. XVI, n. ${ }^{\circ} 22,4$ de abril de 1959), p. 1.

[42] N. Almendros, Días de una cámara, p. 41.

[43] S. A. Russell, «Interview with Néstor Almendros» [31 de marzo de 1973], en Semiotics and Lighting: A Study of Six Modern French Cameramen (Ann Arbor, UMI Research Press, 1981), pp. 84-96.

[44] «Producer Discusses Avant-Garde Films» (Vassar Miscellany News, vol. XXXXIII, n. ${ }^{\circ}$ 26, 6 de mayo de 1959), pp. 1 y 4. 
[45] N. Almendros, «El cine mexicano: desde la etapa industrial hasta la "nueva ola"» (Cuadernos, n. ${ }^{\circ} 89$, octubre de 1964), p. 61.

[46] «Records of the Director of the Summer Programs» (19581959), Special Collections, Middlebury College.

[47] «Escuela española» (Summer Language Schools: Middlebury College Bulletin, marzo de $1960)$, p. 54.

[48] Stephen Freeman, The Middlebury College Foreign Language Schools, p. 346.

[49] Una parte de sus críticas de juventud para dichas revistas aparecen compiladas en Cinemanía, pp. 25-56; el cargo de vicedirector aparece en un folleto de la Cinemateca de Cuba, sin fecha, que nos mostró uno de sus fundadores, Germán Puig, fotógrafo cubano y amigo de Almendros, en su domicilio en Barcelona (entrevista con el autor, 27 de julio de 2015).

[50] N. Almendros, «The Cinema in Cuba) (Film Culture, vol. 2, n. $\left.{ }^{\circ} 3,1956\right)$, p. 21, y «Hollywood va a Reno» (Cinema nuovo, año VI, n. ${ }^{\circ} 118,15$ de noviembre de 1957), pp. 255-257; el texto escrito en California se había publicado previamente, en castellano, como « ¡Hollywood ya no existe!» (Carteles, año 38, n. ${ }^{\circ} 23,9$ de junio de 1957), pp. 37 y 68-70.

[51] N. Almendros, «Montage Seen as Key to Art of the Cinema» (Vassar Miscellany News, vol. XXXXIII, n. ${ }^{\circ} 25,29$ de abril de 1959), pp. 3 y $5-6$.

[52] F. Truffaut, «Une certaine tendance du cinéma français» (Cahiers du cinéma, $n .^{\circ} 31$, enero de 1954), pp. 15-29. a Cuba en verano de 1959, sobre todo La tumba francesa, co-dirigida con Orlando Jiménez Leal en 1961) no pueden entenderse sin la influencia de Deren y del cine experimental americano de aquella época.

Almendros amplió su experiencia como programador de cine durante sus dos estancias en Vermont. En verano de 1958, además de su labor escénica, organizó una serie de proyecciones en el Town Hall Theater, la sala principal de Middlebury, construida en 1884 y con cabida para 600 espectadores. El 9 de julio proyectó $U n$ condenado a muerte se ha escapado (Un condamné à mort s'est échappé, 1956) de Robert Bresson; el día 16, ¡Torero! (1956) de Carlos Velo («raro y hermoso film», como lo describiría más adelante, «el mejor realizado hasta la fecha sobre la fiesta de los toros $»^{45}$ ); y, ya a comienzos de agosto, El general del diablo (Das Teufels General, 1955) de Helmut Käutner. ${ }^{46}$ El verano siguiente exhibiría Rojo y negro (Le rouge et le noir, 1954) de Claude Autant-Lara y, la noche del 22 de julio de 1959, Muerte de un ciclista (1955) de Juan Antonio Bardem. Al igual que el año anterior, en Middlebury se organizaron varias conferencias, conciertos al aire libre, funciones de guiñol y excursiones al lago Dunmore en el cercano parque natural de Bradbury. Una segunda instantánea del profesorado de español en la escalinata del college muestra a Almendros con el grupo docente, esta vez detrás del profesor cubano Roberto Esquenazi. ${ }^{47}$ Años más tarde, Freeman describiría a Almendros como la persona que «descubrió a los estudiantes las técnicas artísticas del cine»». ${ }^{48}$

\section{Crítica de cine: artículos sobre montaje y dirección de fotografía}

Almendros había practicado la crítica de cine con anterioridad, durante sus años de estudiante en La Habana entre 1950 y 1954, en las revistas cubanas El filósofo travieso, Mensuario de arte, literatura y crítica, Noticias de arte y Juventud, así como en forma de notas a la programación de la Cinemateca de Cuba, de la que fue vicedirector por aquellos mismos años. ${ }^{49}$ Durante el período que había pasado estudiando en el Institute of Film Techniques del City College de Nueva York (otoño de 1955) y trabajando en Los Ángeles (primavera de 1956), había escrito además dos textos de mayor madurez para dos importantes revistas internacionales: "The Cinema in Cuba» (El cine en Cuba), un artículo sobre las características históricas de la industria cinematográfica en la isla, se había publicado en 1956 en uno de los primeros números de Film Culture, la revista neoyorquina creada por el — más adelante - cineasta experimental Jonas Mekas; y «Hollywood va a Reno», la crónica algo desalentadora de Almendros tras su paso por la meca del cine americano, había salido a finales del año siguiente en el Cinema nuovo que editaba el crítico marxista Guido Aristarco en Milán. ${ }^{50}$

Durante la primavera de 1959, asentado como profesor y consolidada ya su participación en el cineclub de Vassar, Almendros escribió dos artículos sobre montaje y fotografía de cine que se encuentran entre lo más destacado de su producción como crítico cinematográfico. El artículo sobre montaje, «Montage Seen As Key Element to Art of the Cinema» (El montaje como elemento esencial del arte cinematográfico) se publicó en Vassar Miscellany News a finales de abril de 1959..$^{51}$ En él, Almendros parecía compartir las tesis de Truffaut en su célebre artículo «Une certaine tendance du cinéma français» (Cierta tendencia del cine francés) publicado en Cahiers $d u$ cinéma en $1954,{ }^{52}$ pues, como él, criticaba a directores de la vieja guardia francesa (André Cayatte, por ejemplo) que hacían, más que cine, teatro filmado, y defendía al igual que Truffaut un cine moderno puramente audiovisual. Para Almendros, el medio 


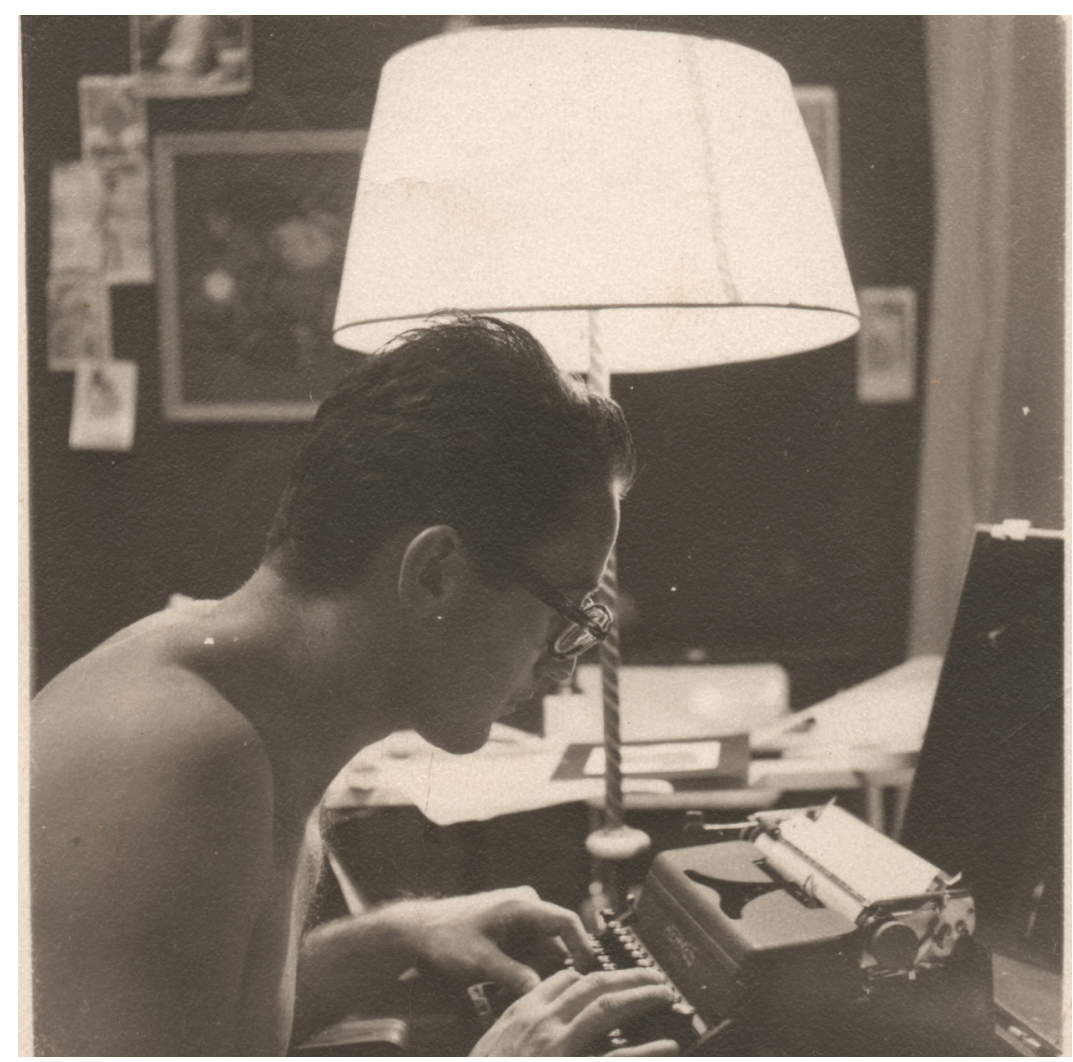

Almendros crítico de cine, ante la máquina de escribir, década de 1950.

cinematográfico encontraba además su verdadero modo de ser en la suma y ajuste de los planos: «El montaje es lo esencial del cine», ${ }^{53}$ sentenciaba. Antes que la puesta en escena, la ontología del cine venía determinada por el montaje, tal y como habían demostrado los grandes cineastas de la escuela soviética (Kuleshov, Pudovkin y, por supuesto, Eisenstein) a los que el catalán dedicaba gran parte de su artículo.

Se trataba de un texto sencillo y claro, donde demostraba su admiración por la vanguardia constructivista soviética. Es significativo que ya entonces Almendros citase la degradación a la que el régimen estalinista había sometido a dicha vanguardia («Conviene señalar, entre paréntesis, que el gobierno soviético finalmente decidió que estos directores habían ido demasiado lejos en sus experimentos formales y, en consecuencia, fueron anatematizados ${ }^{54}$ ), como si pronosticase los propios conflictos de su relación futura con el sector más ortodoxo del Instituto Cubano del Arte e Industria Cinematográficos (ICAIC) fundado en La Habana en marzo de 1959. ${ }^{55}$ De hecho, una versión posterior del texto, en castellano y firmada en París en 1963 (tras su salida de Cuba), ampliaba esa crítica mencionando los distintos tipos de censura que habían sufrido Eisenstein, Pudovkin y Vertov a manos de Boris Shumyatsky, el «ministro de cine» de Stalin. ${ }^{56}$ En esa nueva versión del artículo, titulada «Dos teorías del cine», un Almendros desencantado con la «estética social-realista» matizaría su posición respecto a la primacía del montaje a la hora de definir la ontología del cine, y aceptaría como elemento crucial del medio el uso del plano secuencia tan querido por André Bazin y los críticos de Cahiers.
[53] N. Almendros, «Montage Seen as Key to Art of the Cinema», p. 3 .

[54] Ibid., p. 3

[55] Para una descripción de las fricciones del catalán con el ICAIC, véase su propia versión en Cinemania, pp. 10-16, así como Juan Rodríguez, «Néstor Almendros en el ojo del huracán: el caso de Gente en la playa» (Migraciones y exilios, $\mathrm{n}^{\circ}{ }^{\circ}$, 2015), pp. 63-86.

[56] N. Almendros, «Dos teorías del cine» (Cuadernos, n. ${ }^{\circ} 78$, noviembre de 1963), pp. 65-68, reimpreso en Cinemanía, pp. 272279; para una primera versión del texto en castellano, publicado en La Habana, véase N. Almendros, «El montaje cinematográfico» (Casa de las Américas, n. ${ }^{\circ}$, octubre-noviembre de 1960), pp. $52-55$. 


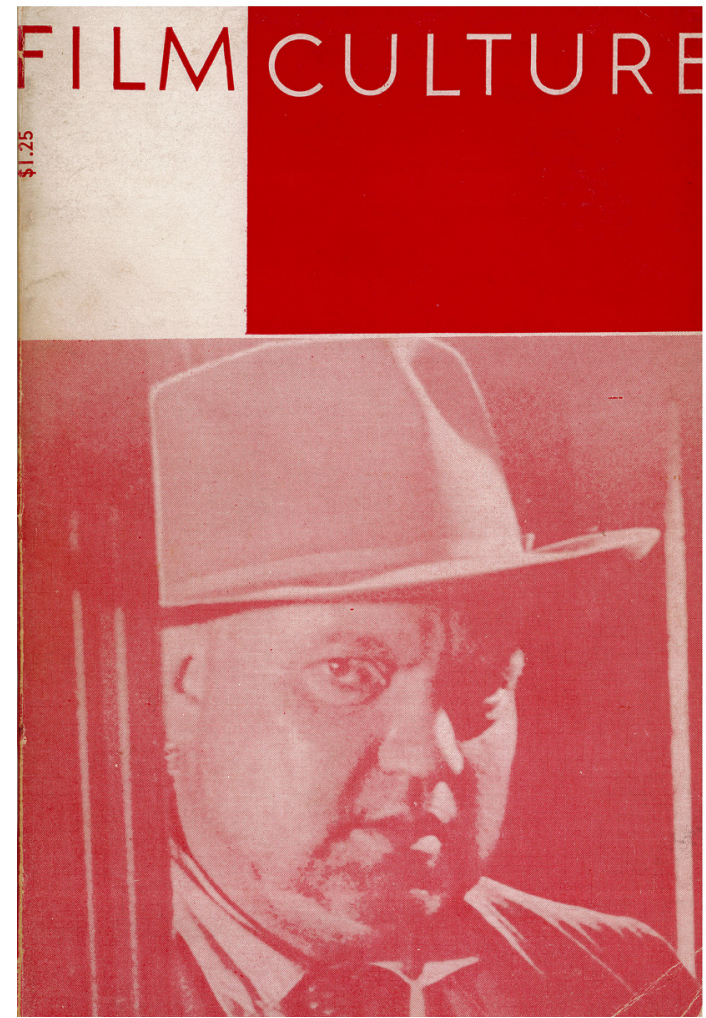

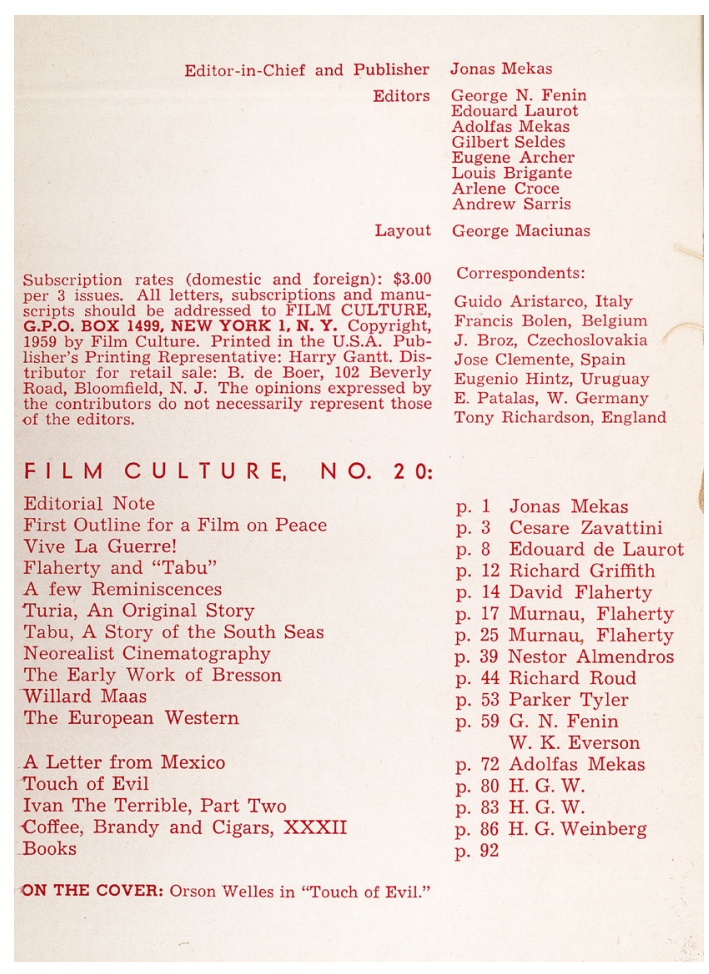

Cubierta e índice del número 20 de Film Culture, otoño de 1959.
[57] N. Almendros, «Neorealist Cinematography» (Film Culture, n. ${ }^{\circ} 20$, [octubre de] 1959), pp. 3943; Almendros lo publica en español, con algún cambio, al poco de regresar a Cuba: «G. R. Aldo y la plástica neorealista: In memoriam» (Revolución, 6 de octubre de 1959), p. 15

[58] N. Almendros, «Neorealist Cinematography», p.40.
El texto sobre dirección de fotografía tiene hoy una importancia especial, pues, visto en retrospectiva, nos informa de las ideas que por entonces preocupaban a Almendros en relación con la disciplina por la cual él mismo obtendría fama internacional más adelante. Se trata de «Neorealist Cinematography» (Cinematografía neorrealista), escrito probablemente en mayo o junio y publicado por Film Culture en octubre de 1959. ${ }^{57}$ En él, Almendros presentaba, por un lado, una serie de ideas generales sobre la historia y estética de fotografía de cine y, por otro, comentaba la obra del cinematógrafo italiano G. R. Aldo, nombre artístico de Aldo Graziati, a quien equiparaba en importancia a otros grandes directores de fotografía de la historia del cine, como Bitzer, Eduard Tissé o Gregg Toland.

Llama la atención el temprano rechazo de Almendros ante las técnicas convencionales de fotografía de cine, que tanto reiteraría durante su vida profesional: no solo a la falsa iluminación basada en las cuatro fuentes primarias de luz (principal, de relleno, de separación y de fondo), sino también al abuso de las lentes de gran angular para aumentar el efecto de profundidad de campo. «Nada más alejado de la visión humana que este monstruoso ojo mecánico con tal precisión óptica» ${ }^{58}$ ironizaba Almendros a propósito de Toland y su entrega al deep focus o profundidad de foco en películas como Ciudadano Kane (Citizen Kane, 1941) de Orson Welles o Los mejores años de nuestra vida (The Best Years of Our Lives, 1946) de William Wyler.

En el análisis de la fotografía de Aldo para La terra trema (La tierra tiembla, 1948) y Senso (1953) de Luchino Visconti, Cielo sobre el pantano (Cielo sulla Palude, 1949) de Augusto Genina y la trilogía Milagro en Milán (Miracolo a Milano, 
1951), Humberto D (Umberto D, 1952) y Estación Termini (Stazione Termini, 1953) del «equipo [Vittorio] de Sica - [Cesare] Zavattini», ${ }^{59}$ Almendros loaba la forma en que, precisamente, el fotógrafo italiano se había enfrentado a las fórmulas hollywoodienses para alcanzar una mayor naturalidad: «La falta de las herramientas técnicas necesarias durante la posguerra produjo una fotografía sin trucos ni ornamentos y, por tanto, forzosamente "realista"». ${ }^{60}$ Fue Aldo quien, por limitaciones materiales, usó por primera vez la luz natural, sin complejos, para evitar la iluminación artificial, cortada y glamurosa del cine hollywoodiense y, por extensión, del imitativo cine fascista de los «teléfonos blancos». Su cinematografía «realista», de acuerdo con Almendros, no era otra cosa que una cinematografía humanista.

Que el joven crítico catalán tenía un talento especial para analizar el aspecto plástico del cine lo demuestra un párrafo particularmente complejo sobre la fotografía en technicolor de Senso:

\begin{abstract}
Aldo usó magistralmente efectos rechazados a menudo por otros fotógrafos: la inclusión en un mismo plano de luz exterior y luz interior con diferentes temperaturas de color (como en aquella escena en que Alida Valli descansa bajo la luz amarillenta de su alcoba mientras la luz blanca del sol entra, tamizada por la cortina de encaje, por la ventana); o la exposición justa para las sombras, dejando la luz del sol sobreexpuesta, un efecto usado en el cine a blanco y negro, pero que en la película a color ofrecía dificultades técnicas como la corta latitud o la distorsión cromática; o, finalmente, las cualidades del color, propias de la pintura al óleo, denso y saturado a la vez, recurriendo a la baja exposición y a la luz difusa del cielo encapotado. ${ }^{61}$
\end{abstract}

La frase con la que cerraba el artículo era, ahora sí, un justo reclamo contra la incipiente teoría del autor de Cahiers: «No es justo atribuir toda la grandeza de un estilo a unos cuantos directores y guionistas: [Roberto] Rossellini, Visconti, Zavattini o [Michelangelo] Antonioni. Que la gloria sea repartida equitativamente y que Aldo reciba una buena parte de ella». ${ }^{43}$

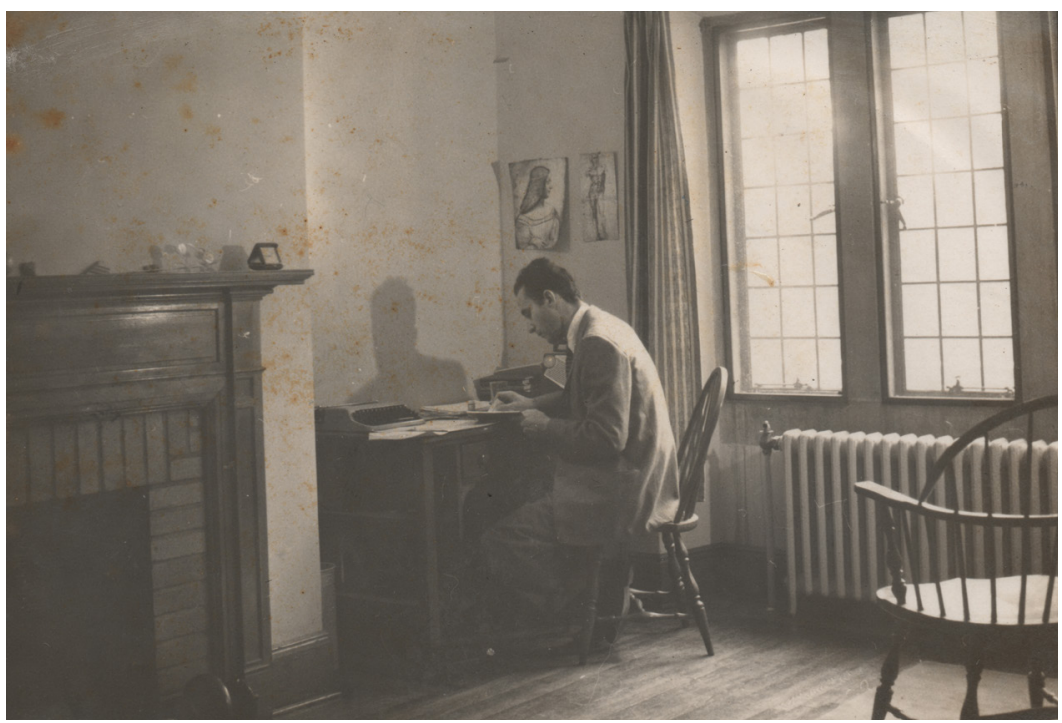

[59] Ibid., p. 41.

[60] Ibid., p. 40.

[61] Ibid., p. 42.

Almendros en su estudio de Vassar College, 1958.

[62] Ibid., p. 43. 
[63] John Cassavetes, «What's Wrong with Hollywood» (Film Culture, n. ${ }^{\circ}$ 19, 1959), pp. 4-5.

[64] N. Almendros, «La nueva ola americana» (Bohemia, año 53, n. ${ }^{\circ} 10,5$ de marzo de 1961), pp. $90-91$.

[65] C. Zavattini, «First Outline for a Film on Peace» (Film Culture, n. ${ }^{\circ}$ 20 [octubre de] 1959), pp. 3-7, y N. Almendros, «Cesare Zavatinni» (Lunes de Revolución, n. ${ }^{\circ}$ 44, 25 de enero de 1960), pp. 5-7; el número 20 de Film Culture también incluía un texto de Richard Roud ( $«$ The Early Work of Bresson», pp. 4452), con quien Almendros estrecharía amistad en la década de 1980 .

[66] N. Almendros, Días de una cámara, p. 40; ambos, Bachman y Fenin, colaboradores de Film Culture.
El número 20 de Film Culture, por lo demás, incluía varias imágenes de Shadows (Sombras, 1958) de John Cassavetes y Pull My Daisy (Sácame la margarita, 1959) de Robert Frank y Alfred Leslie, emblema fílmico de la generación Beat. Ambos films recibirían por entonces el Independent Film Award que otorgaba la revista de Mekas, pues eran consideradas las películas más representativas del cine alternativo neoyorquino, más adelante conocido como el New American Cinema. Almendros rodaría sus propios cortometrajes influido por ambas estéticas: la neorrealista italiana y la del cine no comercial americano. ${ }^{63}$ Un cine, en sus propias palabras, «original», «anticonformista», «en sustitución del producto acaramelado y falso» ${ }^{64}$ de Hollywood, que incluía, además de Shadows y Pull My Daisy, los primeros largometrajes de Shirley Clark, Sidney Meyers y Lionel Rogosin, que Almendros posiblemente descubrió durante su exilio americano. No parece casual que, en este mismo número de Film Culture, publicase un artículo Zavattini, a quien Almendros entrevistaría meses más tarde, a su regreso a Cuba. ${ }^{65} \mathrm{Ni}$ que el catalán mantuviese contacto directo con Mekas, Deren y otras figuras del cine underground del Greenwich Village como Gideon Bachman y George Fenin. ${ }^{66}$ Estas dos tradiciones iban a nutrir su propia filmografía, como lo habían hecho la práctica comisarial y su trabajo como crítico de cine.

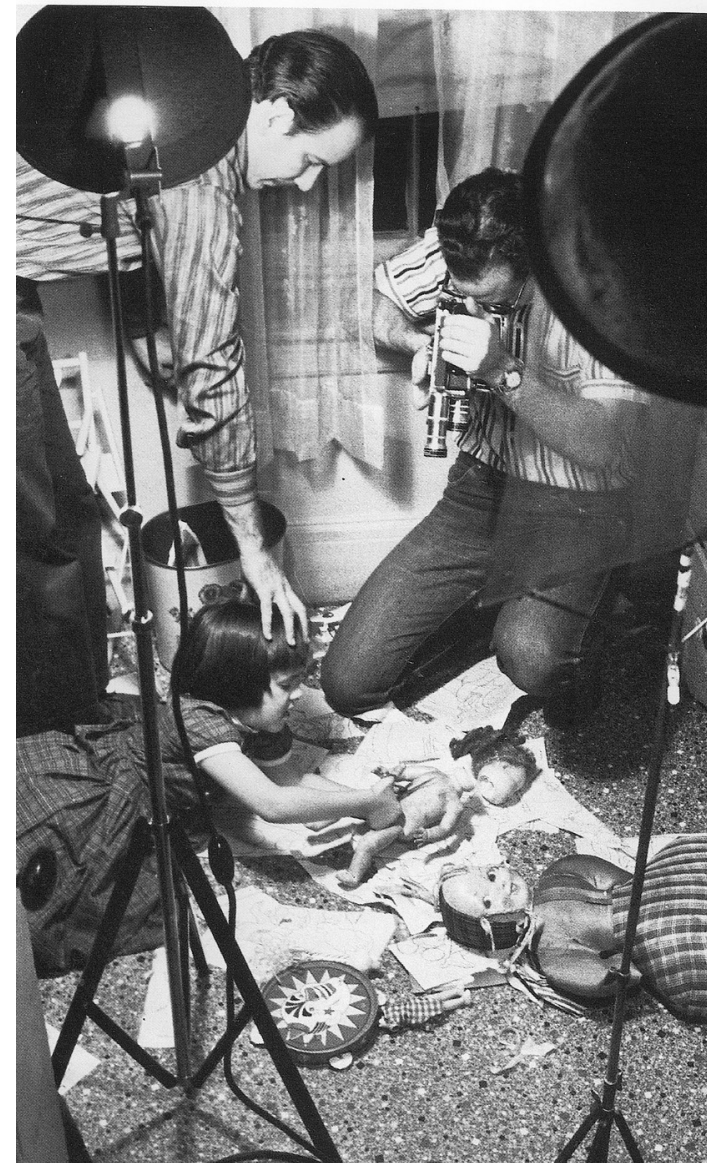

Almendros, con su cámara Bolex, durante del rodaje de The Mount of Luna, Nueva York, octubre-noviembre de 1958.

\section{Cine experimental: The Mount of Luna (1958)}

Como declaró Almendros a Sight and Sound en 1984: «La crítica de cine me permitió analizar el fenómeno de la dirección de fotografía y [...] me enseñó el lenguaje que más tarde necesitaría para establecer un diálogo con los directores; un lenguaje de evaluación estética que expresaba adecuadamente mis ideas sobre el cine». ${ }^{67}$ El propio Almendros iba a poner en acción estas ideas cuando decidió dirigir dos cortometrajes experimentales en Manhattan en otoño de 1958 y primavera de 1959.

El ajetreo y la vida bohemia de Nueva York servían de contrapunto a la tranquilidad de Poughkeepsie. Como había escrito a Alfonso García-Seguí, amigo de infancia en Barcelona: «No hay en el mundo — ni París, ni Roma, ni Ciudad de México, ni Barcelona-, no hay en el mundo una ciudad más llena de vitalidad, energía, cultura e incultura, vicio y puritanismo, libertad y restricción [que] esta maravillosa New York. ¡Deliciosas ambivalencias!». ${ }^{68}$ Fue entonces, en algún momento del otoño de 1958, cuando Almendros se compró una cámara de cine: «Con mis ahorros de profesor, compré una cámara Bolex de $16 \mathrm{~mm}$ y volví a rodar películas amateurs durante los fines de semana». ${ }^{69}$ La primera de ellas fue el cortometraje titulado The Mount of Luna, silente, en blanco y negro, de siete minutos de duración, del que desafortunadamente no se ha conservado ninguna copia y del que solo ha sobrevivido un fotograma y una imagen del rodaje. ${ }^{70}$ Sabemos, eso sí, que Almendros lo rodó 
íntegramente en el apartamento de su hermana en la Calle 56 Oeste, hacia finales de octubre o comienzos de noviembre de 1958, y que estuvo parcialmente producida por The Film Group de Vassar. ${ }^{71}$

Almendros se refirió al cortometraje en muy pocas ocasiones, escuetamente, describiéndolo como «un film experimental underground donde todo se contaba con imágenes de las manos de los actores». ${ }^{72}$ Así se describió también en la revista de alumnos de Vassar: como un ejercicio de montaje «a través del uso imaginativo de nada más que el movimiento y la actividad de las manos para contar una historia». ${ }^{73} \mathrm{El}$ «monte de la luna» es, de hecho, y de acuerdo a la quiromancia, uno de los «montes» de la palma de la mano, situado al lado contrario del pulgar (los palmistas lo estudian para revelar la sensibilidad, intuición y talento artístico de cada persona). Fue su hermana quien, más adelante, describiría The Mount of Luna con mayor detalle, al tratarse de una idea suya:

Le propuse [a Néstor] hacer un argumento filmando sólo las manos de los personajes y así fuimos hilando la trama. En una familia, la mujer se la pasa jugando canasta con las amigas (éramos María Alvear, otras más y yo), el esposo (interpretado por Humberto Arenal) escribe a máquina para ganarse la vida, pero aun así es quien tiene que abrir cuando llaman a la puerta y recoger el periódico mientras la partida de canasta continúa. La niña (la hija de Arenal), malcriada al fin, lo rompe todo. No salía ni una cara. ${ }^{74}$

The Mount of Luna fue pues rodada con actores no profesionales del círculo de familiares y amigos de Almendros. La trama parece sencilla y el tratamiento, abstracto, al no mostrar el film ningún rostro, a la manera de ciertas películas experimentales de Richter, o tal vez emulando a Bresson, cuyos primeros films prestaban tanta atención a las acciones manuales. El fotograma que ha sobrevivido, de hecho, muestra las manos de Arenal cargando un revólver ante una máquina de escribir. ¿Referencia más o menos directa a la máquina mecanográfica como arma del artista? Por varias reseñas del film en la prensa cubana, sabemos además que ese personaje del «esposo» acaba suicidándose con dicho revólver. ${ }^{75}$ ¿Expresión inconsciente autodestructiva del joven Almendros? ¿O comentario irónico sobre la única salida a la monotonía sin rostro de la vida matrimonial?

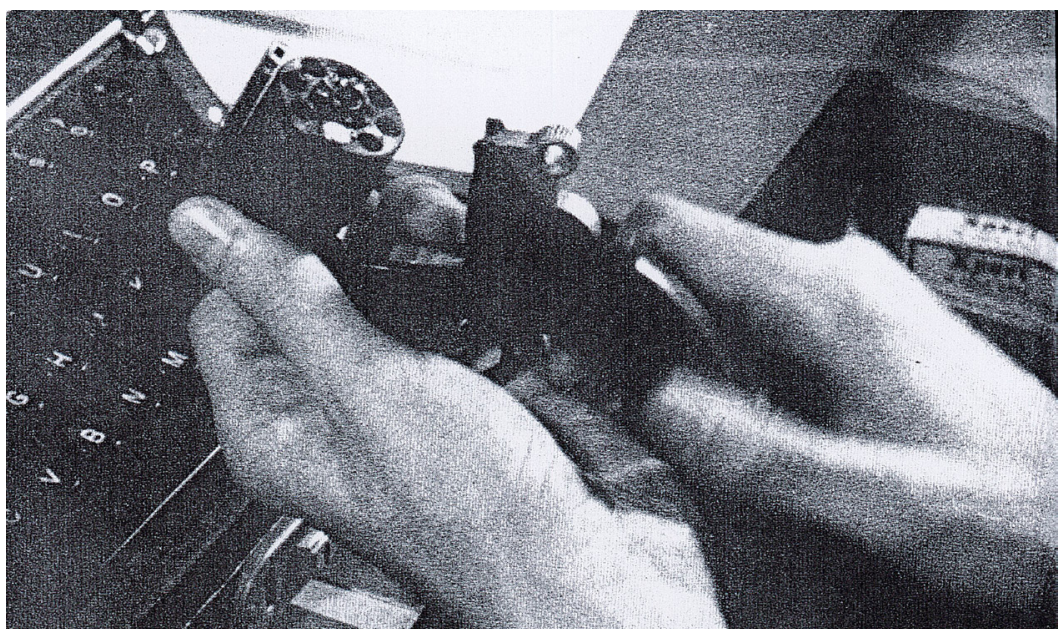

Fotograma del cortometraje The Mount of Luna (Néstor Almendros, 1958).
[67] Jorge Posada, «Photography as Passion: An Interview with Néstor Almendros» (Sight \& Sound, vol. 53, n. $^{\circ} 2$, primavera de 1984), p. 129.

[68] Carta de N. Almendros a A. García-Seguí, 6 de diciembre de 1957, citada por Laureano Bonet, «Unas cartas inéditas de Néstor Almendros», en Isabel de Riquer et al. (eds.), Basilio Losada: Ensinar a pensar con liberdade e risco (Barcelona: Universitat de Barcelona, 2000), p. 188.

[69] N. Almendros, Días de una cámara, p. 40; entre 1950 y 1955 , Almendros había rodado en Cuba cinco cortometrajes en $8 \mathrm{~mm}$ y 16mm: Una confusión cotidiana, co-dirigida por Tomás Gutiérrez Alea a partir de un relato de Franz Kafka; La boticaria, a partir de un relato de Antón Chéjov; Un mónologo de Hamlet, co-dirigida por Ramón Suárez; y Sabá y Nunca, ambas filmadas en color con película Kodachrome.

[70] El fotograma se publica por primera vez en Henri Béhar, «Néstor Almendros: Un directeur de la photographie, à quoi ça sert»» (La Revue du Cinéma, n.o 330, julio de 1978), p. 58; la imagen del rodaje, en la versión italiana de Días de una cámara, titulada Néstor Almendros: Direttore della fotografia (L'Aquila: La Lanterna Magica, 1988), p. 27

[71] «Bio File», p. 2.

[72] N. Almendros, Un homme à la caméra, p. 179.

[73] B. Lachman, «From the Ivory Tower» (Vassar Alumnae Magazine, febrero de 1959), p. 26

[74] E. Mirabal y C. Velazco, «María Rosa mira los Almendros», p. 26; a lo que añade: «The Mount of Luna es una idea mía, y aunque [Néstor] lo incluye en su filmografía, no me da crédito» (p. 26). 
[75] Walfredo Piñera describió el cortometraje, con cierta sorna buñueliana, como «ensayo de un suicidio» en su reseña «Una sesión de cine experimental cubano en el Lyceum Lawn Tennis» (Diario de la Marina, año CXXVIII, 14 de noviembre de 1959), p. 16A; Arturo Agramonte y Luciano Castillo han señalado recientemente que Almendros trataba de «realizar un pequeño estudio del montaje mediante la expresión de una determinada idea -el suicidio de un hombre en la placidez de su hogar tranquiloa través de la imagen solamente», en Cronología del cine cubano IV (1953-1959) (La Habana, Ediciones ICAIC, 2016), p. 545.

[76] «Bio File», p. 2

[77] René Jordán, «Cine experimental» (Excelsior, 12 de noviembre de 1959), s. p.

[78] Fausto Canel, «Notas de una sesión de cine experimental» (Revolución, 12 de noviembre de 1959), p. 14.

[79] N. Almendros, Días de una cámara, p. 40; en el pie de foto del fotograma publicado en $L a$ Revue du Cinéma en 1978, se describía como: «Un film experimental que resultó ser un callejón sin salida», p. 58.

[80] «Bio File», p. 4.

[81] N. Almendros, Días de una cámara, p. 40.
Almendros hizo una primera proyección del cortometraje en el Blodgett Auditorium hacia finales de noviembre del $1958^{76} \mathrm{y}$, más adelante, a su regreso a Cuba, lo presentó en una sesión sobre cine experimental que tuvo lugar en el Lyceum de La Habana el 11 de noviembre de 1959. El film no tuvo en dicha ocasión una buena acogida: René Jordán lo describió en el periódico Excelsior como «un divertimento insípido[,] el género de film de vanguardia que resulta de retaguardia», ${ }^{77}$ y Fausto Canel, en las páginas del diario Revolución, criticó «la excesiva construcción del guión, que no se ha permitido, en una película de montaje como esta, ni la más mínima flexibilidad creadora». ${ }^{78}$ Serían estas críticas al film, además de la ulterior autocrítica de Almendros, las que contribuirían a que el catalán restase importancia al cortometraje a posteriori; más adelante, de hecho, lo calificaría en distintas ocasiones de «pretencioso», útil sólo en la medida en que le hizo «comprender que no era esa la vía a seguir». ${ }^{79}$ Pero conviene indicar que, en 1958 y 1959, The Mount of Luna le sirvió de tarjeta de presentación como cineasta en ciernes en los círculos cinéfilos de Nueva York y La Habana.

En diciembre de 1958, tras acabar el cuatrimestre de otoño en Vassar, Almendros decidió pasar las navidades en Manhattan. El fin de semana del 27 y 28 de diciembre acudió a la convención anual de la Modern Language Association, principal organización del estudio de lenguas y literaturas en el ámbito académico americano, que tuvo lugar en el Hotel Statler-Hilton, frente al Madison Square Garden. ${ }^{80} \mathrm{Al}$ día siguiente, el lunes 29, empezó los preparativos del que sería su segundo cortometraje experimental.

\section{«Primer film de éxito»: 58-59 (1959)}

A diferencia de The Mount of Luna, Almendros siempre se mostró muy satisfecho con 58-59, quizá porque este cortometraje sí disfrutó de una cálida acogida. Afortunadamente, ha sobrevivido una copia del film en $16 \mathrm{~mm}$ en la Cinémathèque québécoise de Montreal y Almendros dejó constancia de su rodaje de modo mucho más detallado. 58-59 se rodó durante la Nochevieja del 31 de diciembre de 1958, entre las 11 de la noche y la 1 de la madrugada, en Times Square, con motivo del célebre festejo de la entrada de Año Nuevo de 1959 (de ahí su título). Para su filmación, en blanco y negro, Almendros usó dos cámaras, su Paillard Bolex y una Bell and Howell que posiblemente era propiedad de su amigo Charles Ramery, quien figuró en los créditos como ayudante de dirección.

De 8 minutos de duración, la película narra los últimos instantes del año 1958 con planos rodados con la cámara al hombro y a través de un montaje muy ágil, que acelera la duración media de plano a medida que avanza el relato. Es dicho ritmo visual, puntuado con una banda de sonido que prescinde en todo momento de la voz en off (a la manera del cine-verdad admirado por Almendros), lo que impone el pulso al cortometraje. Como describió el propio director en Días de una cámara,

realicé 58-59 sobre la víspera del Año Nuevo en Nueva York, los últimos diez minutos antes de la medianoche. Una gran multitud se reúne en el cruce de Times Square y la calle 42 para celebrar el fin de año. La gente espera y hay un crescendo en el montaje hasta que las agujas de los relojes marcan las doce. A todos les invade entonces una locura colectiva, empiezan a abrazarse, a gritar y a tocar silbatos, sonajas, trompetas. Fue mi primera película completa, con sonido, con títulos de crédito y la palabra «Fin» ${ }^{81}$ 
Con estas imágenes de reportaje urbano, Almendros muestra toda la variedad de tipos neoyorquinos: los jóvenes airados, las parejas de enamorados, los fanáticos religiosos, los oficiales de policía, los turistas asiáticos desorientados, las mujeres afroamericanas que miran a la cámara, los borrachos y vagabundos de Times Square... El objetivo era sorprender a la gente en la calle sin que se diese cuenta, rodar de forma espontánea, sin trípode ni focos, utilizando para ello la película negativa Kodak $3 \mathrm{X}$ de gran sensibilidad:

Utilicé con preferencia el espacio que delimitaban las marquesinas de los cines, en donde había mucha luz, casi como en un estudio. Los objetivos eran también de mucha abertura, los Switar f 1.4 de Bolex. En una palabra, aplicaba al cine la técnica ya conocida en la fotografía fija que los americanos denominaban available light, luz de ambiente, sin iluminación suplementaria, en las calles, de noche, con los neones, los anuncios luminosos, las vitrinas de las tiendas. Los viandantes aparecían así en silueta, recortados a veces sobre ese fondo luminoso. ${ }^{82}$

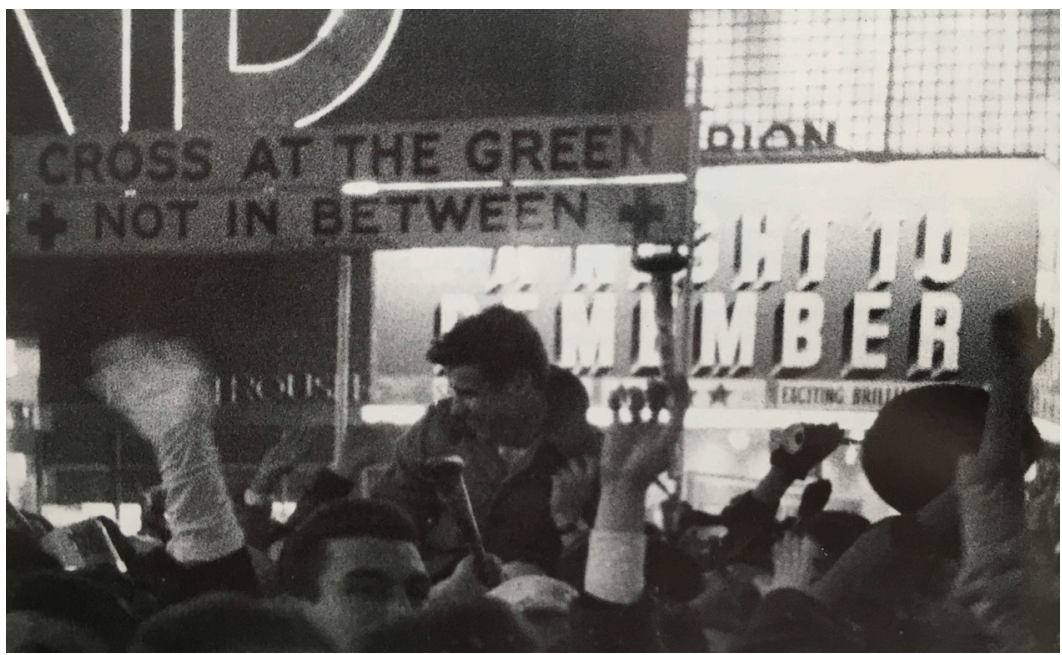

Fotograma del cortometraje 58-59 (Néstor Almendros, 1959).

Algunos de estos elementos novedosos fueron asimilados, más adelante, como convenciones. «En aquel momento — diría Almendros—, era inusitado en el cine este tipo de trabajo en la calle con luz natural de noche. Pero hoy resulta una práctica corriente dejar los fondos con luces de neón "quemadas", sin "equilibrar"»».

58-59 presenta un retablo de rostros y figuras en un momento de celebración y hace un canto - no exento de cierta melancolía (el último plano del film es el de un ciego pidiendo limosna) — a la capital americana de grandes avenidas y oscuros callejones, de brillantes neones y carteles de cine, de rascacielos que se pierden en la niebla y humeantes alcantarillas. La excelente dirección de fotografía y el veloz montaje se combinan con una estridente banda sonora; como señaló René Jordán, «la película tiene un sonido grotesco y ensordecedor, de Día de Juicio Final, en que los ángeles tocan chirriantes trompetas de diez centavos». ${ }^{84}$ Almendros incorpora el sonido en directo, grabado muy probablemente con un magnetófono portátil de marca Nagra, y lo mezcla con efectos sonoros muy variados en la mesa de postproducción (música circense, pitidos de claxon, risas...). Frente al cine experimental, abstracto,
[82] Ibid., pp. 40-41.

[83] Ibid., p. 41; el propio Almendros, de hecho, volvería a emplear dicha técnica de planos nocturnos en exteriores, sin luces de apoyo, en varias escenas memorables de Mi noche con Maud (Ma nuit chez Maud, 1969) de Rohmer.

[84] R. Jordán, «Cine experimental», s. p. 
[85] El primer título del film, luego descartado, fue People (carta de N. Almendros a A. García-Seguí, 21 de abril de 1959, archivo de Daniel Jiménez Schlegl, Barcelona).

[86] Jorge Posada, «Photography as Passion», p. 127-128; Denis Kaufman es el verdadero nombre de Vertov.

[87] N. Almendros, «La nueva ola americana», p. 91.

[88] Para un análisis del primer cine documental y de vanguardia americano, incluidos varios «poemas urbanos», véase Lewis Jacobs, «Experiment in Film» (Hollywood Quarterly, vol. 3, n. ${ }^{\circ}$ 2, invierno de 1947-1948), pp. 111-124.

[89] Subway, rodado en el metro de Nueva York, en $16 \mathrm{~mm}$ y de 8 minutos de duración, fue realizado por los estudiantes del curso de 1955 bajo la supervisión de Yael Woll; para una reseña de este film, en el que quizá participó Almendros (y cuya copia digital se guarda en los archivos del City College), véase Frank Kuentsler, «On the $16 \mathrm{~mm}$ Screen» (Film Culture, vol. 2, n. ${ }^{\circ} 2$, [ verano de] 1956), p. 30.

[90] [«Note»], (Vassar Miscellany News, vol. XXXXIII, n. ${ }^{\circ} 28,20$ de mayo de 1959), p. 2; junto a los films de Almendros, se pasaron otros cortometrajes realizados en 1959: dos films del Child Study Department de Vassar, Fox Hunting (Caza del zorro) de Margaret Summer y Antigua de Lucia Robinson.

[91] David Badder, «Interview with Néstor Almendros» (Film Dope,.$^{\circ} 1$, diciembre de 1972), p. [2].

[92] N. Almendros, Días de una cámara, p. 40.

[93] Una de estas imágenes, procendentes de la colección de Sergio Almendros, se reprodujo por primera vez en L. Cerarols, «Néstor Almendros», p. 37.

[94] F. Canel, «Notas de una sesión de cine experimental», p. 14. en interiores, silente y sin rostros de The Mount of Luna, en 58-59 Almendros se volcó en un cine documental, concreto, filmado en exteriores, sonoro, sobre la «gente corriente» ${ }^{85}$ que se alejaba de excesivos vanguardismos y buscaba en su lugar retratar la vida cotidiana de los neoyorquinos de a pie.

La influencia en 58-59 de la tradición del cine documental poético (desde Vertov a Lorenza Mazzetti) es más que notable. Como declaró Almendros en una entrevista para Sight and Sound más adelante, «cuando eres joven, eres fácilmente moldeable, como si estuvieras hecho de cera. Yo viví, estudié y me empapé de la obra de Aldo. También me influyeron el cine verdad de los hermanos [Boris y Denis] Kaufman; Jean Rouch, el maestro que inspiró la escuela francesa del cinéma vérité; y, last but not least, el Free Cinema británico». ${ }^{86}$ Aunque no lo explicitase en dicha ocasión, en 58-59 también se observa la huella del cine documental neoyorquino del momento, desde The Quiet One (El niño tranquilo, 1948) de Meyers a On the Bowery (En el Bowery, 1956) de Rogosin, pasando por los films del matrimonio Morris Engel-Ruth Orkin -The Little Fugitive (El pequeño fugitivo, 1953) y Lovers and Lollipops (Amantes y piruletas, 1956) - que el catalán conocía de primera mano ${ }^{87}$ Esta tendencia del cine documental estadounidense a menudo había recurrido al rodaje en exteriores, con iluminación natural, y al subgénero de «poema urbano», en el que 58-59 se inserta tan claramente.$^{88}$ De hecho, el film guarda mucha similitud con Subway (El metro, 1955), uno de los cortometrajes colectivos realizados por los estudiantes del Institute of Film Techniques durante el período en el que Almendros había estudiado en dicho centro y donde impartía docencia el propio Meyers. ${ }^{89}$

El jueves 21 de mayo de 1959, a las 8:00 de la tarde, con motivo del último encuentro del cineclub de Vassar, Almendros proyectó The Mount of Luna y 58-59 - esta bajo el título New Year's Eve on Times Square (Nochevieja en Times Square) - en el Blodgett Auditorium. Fue la primera proyección pública de 58-59 en América. ${ }^{90}$ ¿Hubo alguna otra sesión de ambos cortometrajes en la ciudad de Nueva York? Muy probablemente. En una entrevista en 1972, Almendros mencionó un pase ante algunos de los miembros de Film Culture: «Proyecté 58-59 en un café en Nueva York $[\ldots]$ y vinieron todos y al parecer les gustó». ${ }^{91}$ Algo que reiteró más adelante en Días de una cámara: «58-59 fue mi primer éxito — pequeño éxito, claro- en cuanto el grupo de cine experimental de Nueva York se fijó en ella, la alabó y eso me dio ánimos». ${ }^{92}$ Desconocemos cuándo y dónde exactamente tuvo lugar dicha proyección, y cómo tomó forma esa reacción positiva del círculo de Deren y Mekas, pero es posible que fuera en el mes de mayo o junio de 1959 en alguno de los cafés frecuentados por el grupo en Greenwich Village. Quizá también de esa fecha sean unas fotografías que muestran a Almendros en Brooklyn Bridge, junto a Ramery y a un compañero puertorriqueño, rodando con su cámara de cine de $16 \mathrm{~mm}$ las vistas del puente neoyorquino. ${ }^{93}$

Por lo demás, 58-59 también se proyectó en la sesión de cine experimental del Lyceum de La Habana en noviembre de 1959, junto al cortometraje Diez centavos (1959) de Antonio Cernuda y los mediometrajes Uno, el solitario (1959) de Plácido González y El Mégano (1955) de Julio García Espinosa (con la colaboración de Gutiérrez Alea). De hecho, según los asistentes a la muestra, 58-59 fue el film que tuvo mayor impacto. Canel escribió al día siguiente de la proyección que el cortometraje de Almendros fue «la mejor de las cintas presentadas en la sesión del Lyceum, y el intento más importante y logrado dentro de nuestro cine experimental» $;{ }^{94}$ Walfredo Piñera lo describió como la película «que mayor impresión nos causó por su mérito 


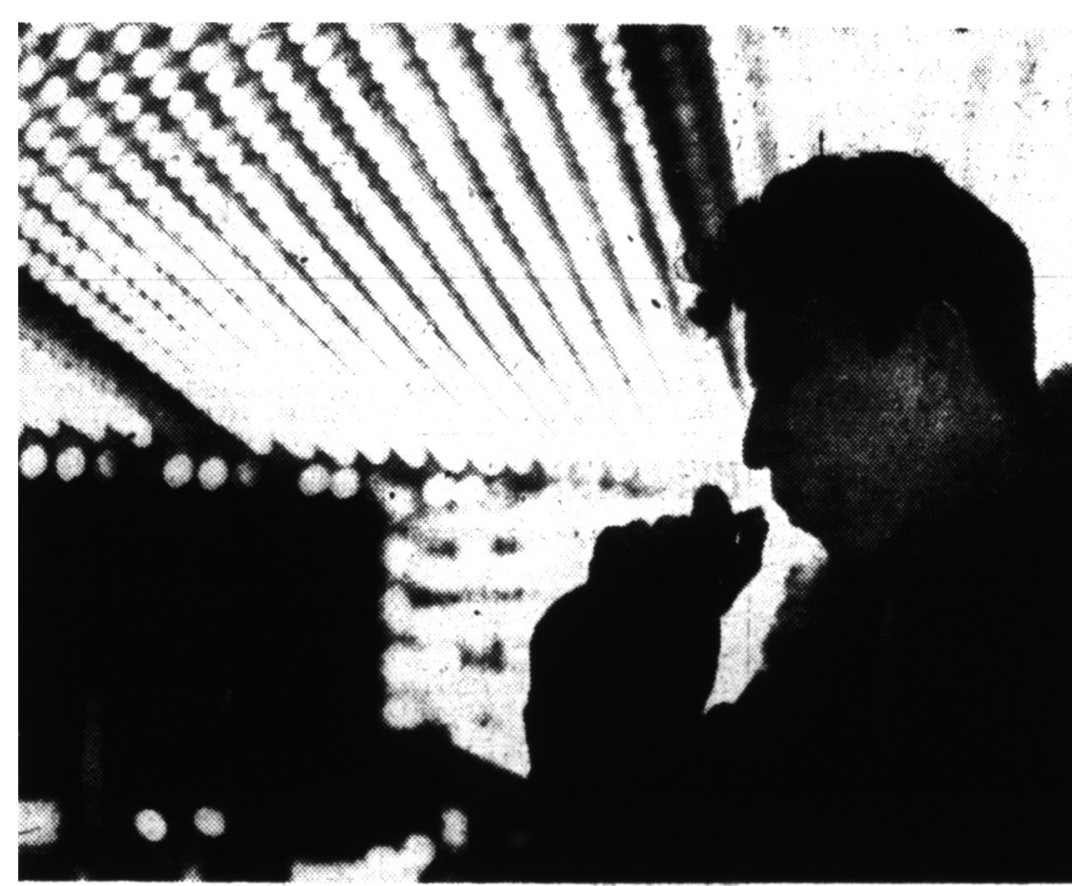

"58-59", es sin lugar a dudas la mejor de las cintas presentadas en el Lyceum, y el intento más importante y logrado dentro de nuestro cine experimental.

Fotograma del cortometraje 58-59 (Néstor Almendros, 1959), con pie de foto de Fausto Canel y reproducido en el diario Revolución, La Habana, 12 de noviembre de 1959, p.14.

como testimonio social» $9{ }^{95}$ y Jordán, como «el film del paroxismo, la apoteosis de la soledad en compañía: Almendros ha sabido darle a su película esa corriente de angustia que es el substrato de toda gran alegría colectiva y exhibicionista». ${ }^{96}$

Una cuarta reseña de 58-59, publicada sin firma en la revista habanera Carteles (pero escrita muy posiblemente por el director de la sección de cine de dicha publicación, Guillermo Cabrera Infante), decía:

Almendros no tiene miedo a casi nada y su cámara vuela, pasea, nada, corre, mira arriba y abajo y se siente tan cómoda en la mano como en un carril. Luego, en el cuarto de montaje, ha olvidado los conceptos de los seguidores de Eisenstein y en vez de colocar una foto junto a la otra, deja que la acción fluya con la misma suavidad y con idéntica naturalidad a la de la cámara-ojo; lo que la cámara ve es lo que el espectador ve ${ }^{97}$.

Cabrera Infante, de hecho, contraponía la visión del film de Almendros en 58-59 a la de Gutiérrez Alea y García Espinosa en El Mégano, que describía ahora como «rígida, antinatural y no exenta de cierta ampulosidad mecánica», y cuya intención «neorrealista» consideraba ya pasada de moda.$^{98} \mathrm{El}$ comentario revelaba una temprana divergencia de lo que, más adelante, se convertiría en una profundísima sima entre el cine cubano filmado dentro y fuera de la isla.

En cualquier caso, la relevancia de 58-59 se debe hoy a varios elementos: el histórico (combinación del docudrama americano de sesgo experimental y de las diversas expresiones del cine-verdad), el tecnológico (aparición de las cámaras portátiles de
[95] W. Piñera, «Una sesión de cine experimental», p. 16A.

[96] R. Jordán, «Cine experimental», s. p.

[97] [G. Cabrera Infante], «Cine experimental cubano» (Carteles, año 41, n. $^{\circ} 7,14$ de febrero de 1960), p. 44; Almendros volverá a proyectar 58-59 en la Cinémathèque Française, por mediación de Jean Rouch, en otoño de 1962; en Barcelona, en la Sala Aixelá, a mediados de la década de 1960 —véase P. Gimferrer, «Antaño y ahora: Néstor Almendros» (Destino, año 41, n. ${ }^{\circ} 2167,19$ de abril de 1979), p. 32-y, años más tarde, en la retrospectiva de su trabajo organizada por el Museum of the Moving Image de Nueva York (enero-febrero de 1989).

[98] [G. Cabrera Infante], «Cine experimental cubano», p. 44. 


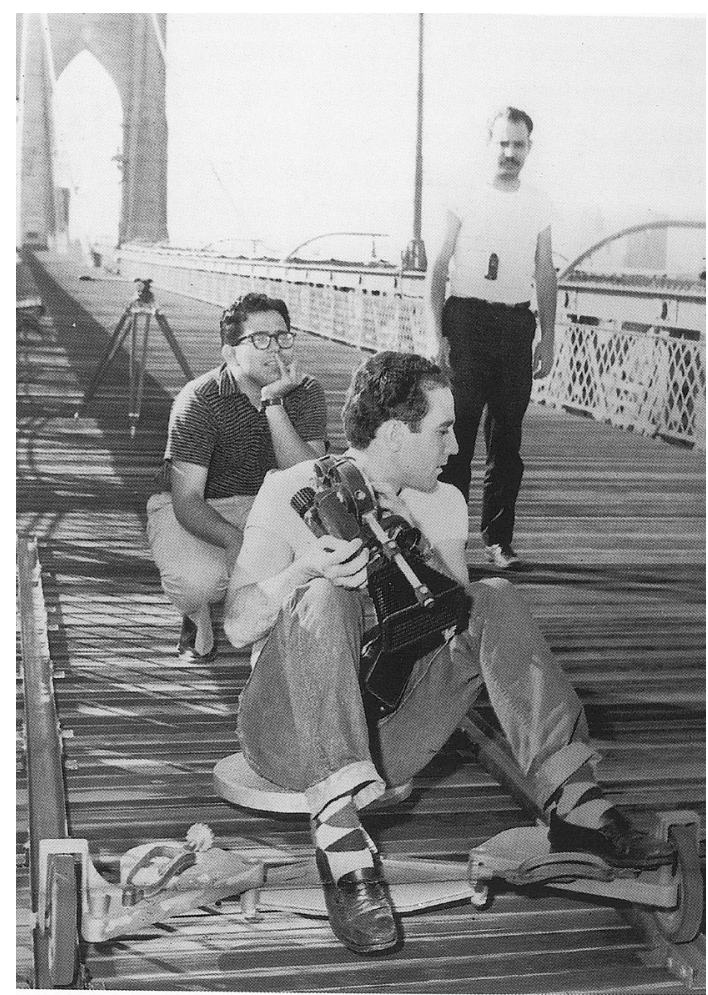

Almendros, con una cámara Arriflex de $16 \mathrm{~mm}$, y Charles Ramery, con visor, rodando un film experimental inacabado en el puente de Brooklyn, Nueva York, hacia verano de 1959.
$16 \mathrm{~mm}$, del celuloide Kodak 3X, de las grabadoras Nagra) y el estético (el indudable talento de Almendros para llevar a la fotografía de cine varias técnicas establecidas en la fotografía fija por artistas como Henri Cartier-Bresson o Robert Frank). Todas estas características hacen del cortometraje una pequeña joya del cine neoyorquino del momento y lo convierten, sin duda, en un título esencial del cine español en el exilio.

\section{Coda}

«Supongo que, de haber decidido quedarme en Estados Unidos - diría Almendros en Días de una cámara-, hubiera llegado a ser uno de los cineastas underground de la escuela de Nueva York, dada mi afinidad con aquel movimiento que apenas comenzaba. Pero esto ocurría en 1959, el año del triunfo de Castro en Cuba». ${ }^{99}$ Fueron miembros del propio gabinete revolucionario los que establecieron un primer contacto con Almendros al poco de formarse el nuevo gobierno en enero de 1959. En su primer viaje oficial al extranjero como Primer Ministro de Cuba, Fidel Castro visitó Estados Unidos, en el mes de abril, junto a una comitiva de periodistas e intelectuales que incluía a Cabrera Infante, Teté Casuso, Carlos Franqui y el fotógrafo Alberto Korda. Tras el frío encuentro de Castro con el vicepresidente Richard Nixon en Washington, la comitiva viajó a Nueva York, donde el joven líder cubano fue recibido con verdadero candor popular (1.500 personas a su llegada a Penn Station, 16.000 personas en su discurso en Central Park, admiración internacional tras su rueda de prensa en sede de las Naciones Unidas...). ${ }^{100}$

Fue entonces, la última semana de abril de 1959, cuando Almendros se reunió con varios miembros de dicha comitiva. Se conservan dos fotografías de un encuentro ante del Arco del Triunfo de Washington Square, en el que estuvieron presentes, entre otros, Cabrera Infante, Humberto Arenal y el periodista Óscar Hurtado. Fueron ellos posiblemente quienes informaron a Almendros con más detalle de la recién fundación del ICAIC y de los proyectos de rodar Cuba baila de García Espinosa e Historias de la Revolución de Gutiérrez Alea a partir de un guion co-escrito por el propio Arenal. ${ }^{101}$ La nueva industria del cine cubano, en manos ahora de antiguos amigos y miembros de su generación, ofrecía a Almendros la posibilidad de hacerse director de cine profesional: «Decidí volver a La Habana. La revolución significaba una atracción irresistible». ${ }^{102}$

A finales del verano de 1959, Almendros dejó Nueva York y regresó a Cuba. Ni por asomo podía imaginar, al poner de nuevo sus pies en la isla, que aquella «atracción irresistible» con la Revolución se iba a disipar — y de qué manera — durante los meses que se avecinaban. Los acontecimientos de los tres próximos años, de hecho, marcarían su destino para siempre.
[102] N. Almendros, Días de una cámara, p. 41. 


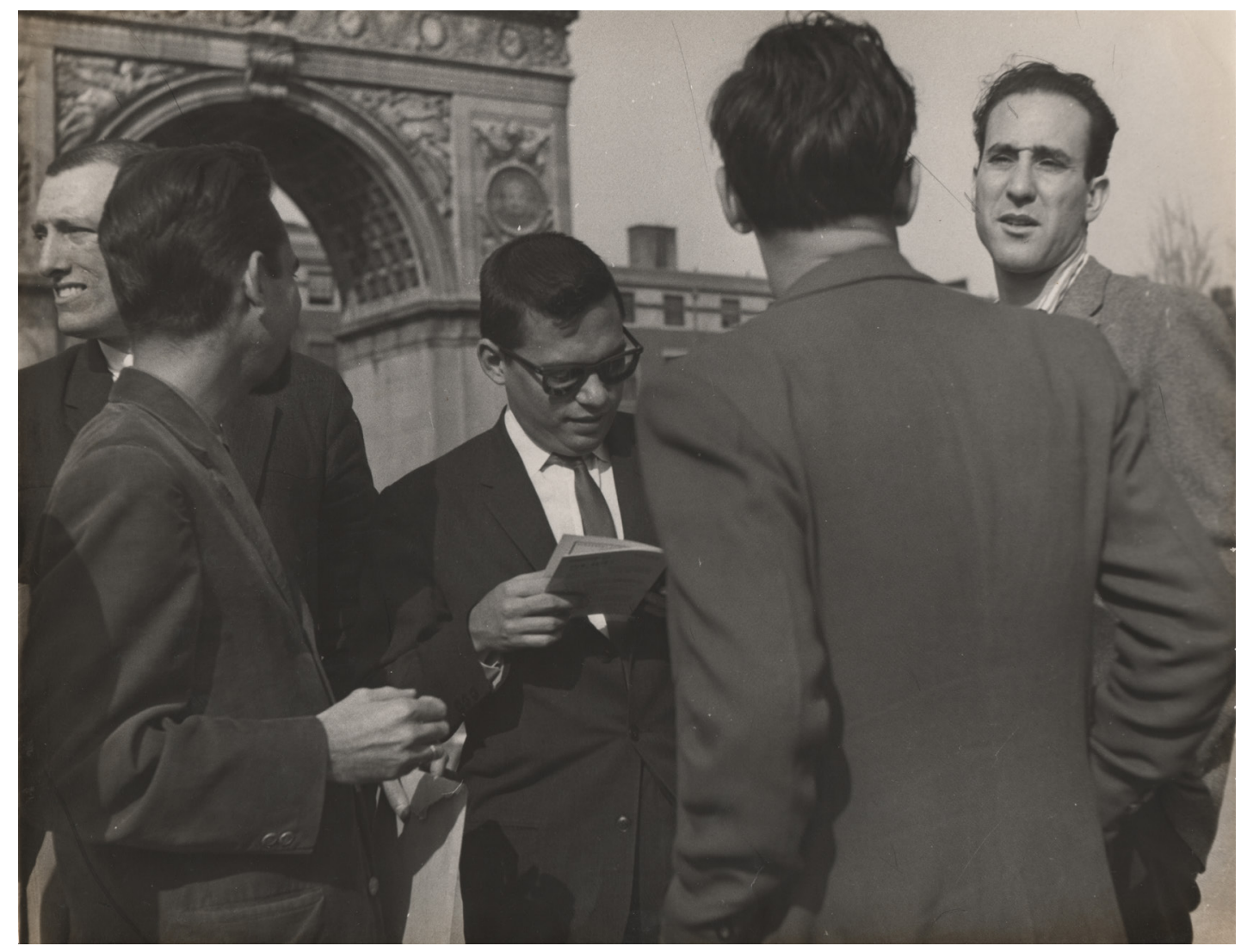

Óscar Hurtado, Humberto Arenal, Guillermo Cabrera Infante y Néstor Almendros en Washington Square, Nueva York, abril de 1959.

\section{FUENTES}

Carpeta Néstor Almendros, Special Collections, Vassar College (Poughkeepsie, Nueva York)

Records of the Summer Programs, Special Collections, Middlebury College (Middlebury, Vermont).

Fons Josep Ferrater Mora, Universitat de Girona (Girona).

Archivo de Belén Piqueras, Almansa.

\section{BIBLIOGRAFÍA}

Agramonte, Arturo, y Castillo, Luciano, Cronología del cine cubano IV (1953-1959), La Habana, Ediciones ICAIC, 2016.

Almendros, Néstor, «The Cinema in Cuba» (Film Culture, vol. 2, n. ${ }^{\circ} 3,1956$ ), p. 21.

-, «iHollywood ya no existe!» (Carteles, año 38, n. ${ }^{\circ} 23,9$ de junio de 1957), pp. 37 y $68-70$. 
—, «Hollywood va a Reno» (Cinema nuovo, año VI, n. ${ }^{\circ}$ 118, 15 de noviembre de 1957), pp. 255-257.

—, «Estudio fonético del español en Cuba (región occidental)» (Boletín de la Academia Cubana de la Lengua, vol. II, n. ${ }^{\circ}$ 1-2, enero-junio de 1958), pp. 138-176.

— et al., «Letter to the Editor» (Vassar Miscellany News, vol. XXXXIII, n. ${ }^{\circ} 14,14$ de enero de 1959), p. 2.

-, «Montage Seen as Key to Art of the Cinema» (Vassar Miscellany News, vol. XXXXIII, n. ${ }^{\circ} 25,29$ de abril de 1959), pp. 3 y 5-6.

—, «Neorealist Cinematography» (Film Culture, n. ${ }^{\circ}$ 20, [octubre de] 1959), pp. 39-43.

—, «G. R. Aldo y la plástica neorealista: In memoriam» (Revolución, 6 de octubre de 1959), p. 15.

—, «Cesare Zavatinni», (Lunes de Revolución, n. ${ }^{\circ}$ 44, 25 de enero de 1960), pp. 5-7.

—, «El montaje cinematográfico» (Casa de las Américas, n. ${ }^{\circ}$ 3, octubre-noviembre de 1960), pp. 52-55.

—, «La nueva ola americana» (Bohemia, año 53, n. ${ }^{\circ}$ 10, 5 de marzo de 1961), pp. 90-91.

—, «Dos teorías del cine» (Cuadernos, n. ${ }^{\circ}$ 78, noviembre de 1963), pp. 65-68.

—, «El cine mexicano: desde la etapa industrial hasta la "nueva ola"» (Cuadernos, n. ${ }^{\circ} 89$, octubre de 1964), pp. 57-62.

-, Cinemanía (Barcelona, Seix Barral, 1992).

—, Días de una cámara (Barcelona, Seix Barral, 1993).

BADDER, David, «Interview with Néstor Almendros» (Film Dope, n. ${ }^{\circ}$ 1, diciembre de 1972), s.p.

BÉHAR, Henri, «Néstor Almendros: Un directeur de la photographie, à quoi ça sert» (La Revue du Cinéma, n. ${ }^{\circ} 330$, julio de 1978), p. 58.

Bonet, Laureano, «Unas cartas inéditas de Néstor Almendros», en Isabel de Riquer et al. (eds.), Basilio Losada: Ensinar a pensar con liberdade e risco (Barcelona, Universitat de Barcelona, 2000), pp. 185-192.

CABrera Infante, Guillermo, «Cine experimental cubano» (Carteles, año 41, n. ${ }^{\circ} 7$, 14 de febrero de 1960), p. 44.

Canel, Fausto, «Notas de una sesión de cine experimental» (Revolución, 12 de noviembre de 1959), s. p.

Castaño, Juan A., et al., Néstor Almendros (Las Palmas, Cuadernos de Filmoteca Canaria, 2003).

Cerarols, Lluís, «Néstor Almendros: Biografia d'un home de cinema» (Modilianum, n. ${ }^{\circ} 35$, segundo semestre de 2006), pp. 33-50.

Freeman, S., The Middlebury College Foreign Language Schools, 1915-1970: The Story of a Unique Idea (Middlebury, Middlebury College Press, 1975).

Gimferrer, Pere et al., Néstor Almendros (Barcelona, Filmoteca de Catalunya, 1993).

Gosálvez, Antonio, Néstor Almendros en Sevilla (Sevilla, Filmoteca de Andalucía, 1999).

Gras, Dunia, «Introducción», en El arte de la nostalgia: Cartas de Néstor Almendros a Guillermo Cabrera Infante (Madrid, Verbum, 2013), pp. 9-35.

Jordán, René, «Cine experimental» (Excelsior, 12 de noviembre de 1959), s. p.

Mirabal, E., y Velazco, C., «María Rosa mira los Almendros» (Revolución y cultura, época $V$, n. $^{\circ} 4$, octubre-diciembre de 2010), pp. 21-28.

PIÑERA, Walfredo, «Una sesión de cine experimental cubano en el Lyceum Lawn Tennis» (Diario de la Marina, año CXXVIII, 14 de noviembre de 1959), p. 16A. PosADA, Jorge, «Photography as Passion: An Interview with Néstor Almendros» (Sight 
\& Sound, vol. 53, n. ${ }^{\circ} 2$, primavera de 1984), pp. 124-129.

RoDRÍGUEZ, Juan, «Los exiliados republicanos y el cine (una reflexión historiográfica)» (Iberoamericana, vol. XII, n. ${ }^{\circ} 47,2012$ ), pp. 157-168.

—, «Néstor Almendros en el ojo del huracán: el caso de Gente en la playa» (Migraciones y exilios, $\left.\mathrm{n}^{\circ}{ }^{0} 15,2015\right)$, pp. 63-86.

Russell, S. A., «Interview with Néstor Almendros» [31 de marzo de 1973], en Semiotics and Lighting: A Study of Six Modern French Cameramen (Ann Arbor, UMI Research Press, 1981), pp. 84-96.

Recibido: 1 de noviembre de 2019

Aceptado para revisión por pares: 13 de marzo de 2020

Aceptado para publicación: 31 de agosto de 2020 